\title{
Exploring the relationship between speech perception and production across phonological processes, language familiarity, and sensory mo- dalities
}

Judith Schmitz $^{\mathrm{a}^{*}}$, Begoña Díaz ${ }^{\mathrm{a}^{*}}$, Karla Fernández Rubio ${ }^{\text {a }}$, and Nuria Sebastian-Galles $^{\text {a }}$

${ }^{a}$ Center for Brain and Cognition, Pompeu Fabra University, Barcelona, Spain

* Correspondence:

* Judith Schmitz, Center for Brain and Cognition, Pompeu Fabra University, C. Ramon Trias Fargas 25-27, 08005 Barcelona, Spain, E-mail: judith-schmitz@gmx.net

* Begoña Díaz, Center for Brain and Cognition, Pompeu Fabra University, C. Ramon

Trias Fargas 25-27, 08005 Barcelona, Spain, E-mail: begona.diaz@upf.edu

Acknowledgments: We thank Robert Frank de Menezes, Mireia Martín, and Aina Pinyol for help with the data acquisition, Miguel Burgaleta for help with the factor analysis, Carolina Sánchez-García and Salvador Soto-Faraco for sending us the stimuli of the audio-visual task, and Silvia Blanch and Xavier Mayoral for the technical support. This research was funded by grants from the European Commission Seventh Framework Programme (FP7/2007-2013): ERG grant agreement number 323961 (UNDER CONTROL); the Spanish Ministerio de Economía y Competitividad (PSI201566918-P) and the Catalan Government (SGR 2014-1210) awarded to NSG. NSG also received the "ICREA Acadèmia" prize for excellence in research, funded by the Generalitat de Catalunya. BD received funding from the People Programme (Marie Curie Actions) of the European Union's Seventh Framework Programme (FP7/20072013) under REA grant agreement n 32867 and a postdoctoral fellowship from the Spanish Government (Juan de la Cierva fellowship JCI-2012-12678). 
Current speech perception models disagree over the role of speech production in speech perception. In the current study we aimed to characterize the relationship between speech perception and production by testing a large sample of early and highly proficient Spanish-Catalan bilinguals in a variety of speech perception and production tasks. Speech perception was measured for different phonological processes (sub-lexical and phono-lexical), different language familiarities (native, second, and unknown language), and different sensory modalities (auditory and audio-visual). Speech production ability was assessed in the second language. Non-linguistic auditory and sensory motor abilities were also measured. We used factor analysis to look at the relations between the variables. Results showed a tight relationship between speech perception and production measurements, which was present across phonological processes and language familiarities but was independent of audio-visual and non-linguistic (auditory and sensory-motor) skills.

Keywords: speech perception, speech production, phonological processes, language familiarity, audio-visual integration 


\section{Introduction}

The role of speech production in speech perception is an open issue. Traditionally, researchers in the field of language have proposed that speech perception and production are two different processes and, consequently, study them separately. This traditional separation of the fields was encouraged by the early observation that patients with brain damage in the frontal lobe had problems in speech production (Broca's aphasia), while patients with brain damage in the temporal lobe showed problems in speech perception (Wernicke's aphasia) (for a review see Gazzaniga, Ivry, \& Mangun, 2002). This dissociation of the neuroanatomical location of the two speech processes led to the development of separate psycholinguistic models for speech perception (Klatt, 1979; MarslenWilson \& Welsh, 1978; McClelland \& Elman, 1986; Norris, 1994) and production (Dell, 1986; Fromkin, 1971; Levelt, 1989; Levelt, Roelofs, \& Meyer, 1999). This view of speech perception and production as independent processes has been challenged by recent studies that show an involvement of production processes in speech perception (Fadiga, Craighero, Buccino, \& Rizzolatti, 2002; Watkins, Strafella, \& Paus, 2003, Pulvermüller et al., 2006; D’Ausilio, Pulvermüller, Salmas, Bufalari, Begliomini, \& Fadiga, 2009; Ito, Tiede, \& Ostry, 2009; Möttönen \& Watkins, 2009; Kittredge \& Dell, 2016). The debate revolves around whether the role of the production system is essential to speech perception (Pulvermüller \& Fadiga, 2010), or whether it is epiphenomenal (Lotto, Hickok, \& Holt, 2009; Scott, McGettigan, \& Eisner, 2009). The present study investigates the role of speech production in perception in a novel way: it analyzes the performance of the same participants in a wide variety of tasks. These tasks assessed speech perception abilities across participants' languages, phonological processes and sensory modalities; they were also used to investigate complex patterns of interaction with production skill by means of factor analysis. 
Traditionally, two basic general views have been put forward regarding the relationship between speech perception and production. Most Psycholinguistic models developed in the 20th century postulated that speech perception was separate from production. For these models, speech perception was based solely on the processing of acoustic information (e.g., the Cohort model by Marslen-Wilson and Welsh (1978), the TRACE Neural network proposed by McClelland and Elman (1986), and Norris' (1994) SHORTLIST). These models assumed the computation of a series of phonetic/phonological representations between the acoustic signal and the lexicon though they differed significantly in how much interactivity was present in the system. Dissociations in neurological patients supported the existence of separate input and output paths (Caramazza, Miceli, Villa, \& Romani, 1987; Hillis, Rapp, \& Caramazza, 1999), therefore reinforcing the view that there was no need to postulate any cross-talk between perception and production at early stages.

Other views such as The Motor Theory (Liberman \& Mattingly, 1985) and the direct-realist theory (Fowler, 1986) suggested that the high acoustic variability of the speech signal could not provide invariant phoneme percepts and posited that speech perception was based on the analysis of articulatory gestures. These models shared the notion that there was a common underlying articulatory code for speech perception and production and, therefore, that speech production was essential for speech perception. Initially, motor theories of speech perception were a minority view but they were revisited when Rizzolatti and coworkers identified a type of motor neuron in the macaque brain, the mirror neurons, that fired not only when the monkey performed an action but also when it watched an agent performing the same action (di Pellegrino, Fadiga, Fogassi, Gallese, \& Rizzolatti, 1992). Some authors claimed that this type of neuron (or 
their human counterpart) play a pivotal role in language by combining speech perception and production in the same entity, thereby allowing for shared neuronal mechanisms (Pulvermüller \& Fadiga, 2010). In the same vein, several studies have supported the existence of a neural substrate that integrates speech perception and production (Fadiga et al., 2002; Watkins et al., 2003; Pulvermüller et al., 2006; D’Ausilio et al., 2009). For instance, using trasncraneal magnetic stimulation, Fadiga et al. (2002) showed that listening to words containing phonemes articulated with a tongue movement (such as " $r$ ") results in higher excitation of the tongue representation in the motor cortex compared to listening to words containing phonemes that do not involve the tongue muscles (such as “f”).

Emergent conceptualizations of the speech perception system have evolved to accommodate the increasing evidence for the influence of articulatory information in speech perception. The Perception-for-Action-Control Theory (PACT) (Schwartz, Basirat, Ménard, \& Sato, 2012) posits that the basic units of speech perception convey multimodal cues such as articulatory, auditory, and visual information. Based on the observation that both speech perception and speech production shape the speech sounds, the model assumes that we perceive "perceptually-shaped gestures" or "perceptuomotor units". Other views suggest that the basic units of speech perception are auditory and that the role of the speech production system is to assist speech perception by providing feedback predictions about the incoming speech (Bever \& Poeppel, 2010; Hickok, Houde, \& Rong, 2011; Skipper, Devlin, \& Lametti, 2017). A predictive role of the production system has in fact been put forward not only for speech perception but for all processes involved in language comprehension (Pickering \& Garrod, 2013). However, the debate still revolves around whether the role of the production system as a forward model for speech perception is a by-product of task demands (Hickock et al, 
2011), or an integral part of the speech perception system that is used dynamically, depending on the context demands (Skipper et al., 2017). To accommodate the participation of motor areas in speech perception, more recent neurocognitive models of language have moved away from the traditional neurocognitive models restricted to Broca's and Wernicke's areas (Hickok \& Poeppel, 2007; Rauschecker \& Scott, 2009; Friederici, 2011; Price, 2012; Skipper, 2017). For instance, the Hickok and Poeppel's (2007) Dual Stream model proposes two routes for speech perception: the ventral route, which analyzes speech based on acoustic properties, and the dorsal route, which analyzes motor information. In this model, speech perception is fundamentally based on the processing of auditory information; however, the model allows for articulatory influences under some circumstances, such as noisy environments, when the redundant articulatory cues may help the processing of poor acoustic information (Hickok et al., 2011).

The models reviewed here all involve native language processing, but models of L2 speech perception also postulate interactions between speech perception and production processes.

\section{The relation between $L 2$ speech perception and production}

The most influential L2 speech processing models are the Perceptual Assimilation Model (PAM) from Best (Best, 1995; Best \& Tyler, 2007), and the Speech Learning Model (SLM) from Flege (Flege, 1995). Both models make similar predictions concerning the ease with which a new phoneme can be learned. They propose that if a nonnative phoneme is distant from the native phonemes, it will be perceived and produced relatively well but if it is close to a native category (or a non-native phoneme contrast falls within the same native category) discrimination will be difficult and production 
inaccurate. Examples of phoneme contrasts that are very difficult to discriminate by L2 learners because they fall within the same category in the native language are the English /r-1/ contrast for Japanese natives (Miyawaki et al., 1975), and the Catalan /e-c/ contrast for Spanish natives (Pallier, Bosch, \& Sebastian-Galles, 1997). However, the models differ in their axiomatic principles. Best's PAM is a motor model and assumes that the acoustic signal is translated into an articulatory code prior to phoneme recognition. Accordingly, difficulties in perceiving an L2 phoneme should be due to difficulties in producing the same phoneme or in extracting the corresponding articulatory gesture from the acoustic input. On the other hand, Flege's SLM is an acoustic model, which postulates that L2 phoneme categories have to be accurately perceived before they can be produced. Thus, problems in producing an L2 phoneme should be caused by inaccurate categories for perceiving the same phoneme.

Despite the relationship between speech perception and production proposed in both PAM and SLM, the empirical evidence for such a strong relationship is inconsistent. Previous studies that assessed the correlation between the two abilities in L2 learners showed a wide range of variation in their results, from strong correlations (Flege, MacKay, \& Meador, 1999) to moderate correlations (Levy \& Law, 2010; Rallo Fabra \& Romero, 2012), or no correlations at all (Kartushina \& Frauenfelder, 2014; Peperkamp \& Bouchon, 2011). In the following section we describe two studies in detail, corresponding to the extremes of high correlation and no correlation between L2 speech perception and production.

Flege et al. (1999) found high to moderate relationships between L2 and L1 speech perception and L2 production abilities. They studied 72 highly proficient Italian (L1)-English (L2) bilinguals that varied in the L2 age of acquisition (AoA) but had spent at least 12 years living in the L2 country. The authors measured L2 and L1 
perception by means of a discrimination task of L2 English contrasts (/ae/-/L/, /A/-/p/, /i/-

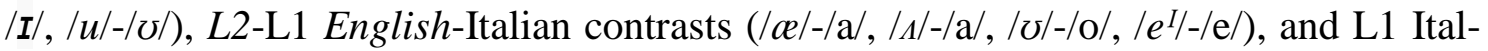
ian contrasts (/u/-/o/, /e/-/a/, /u/-/i/), and production ability of ten L2 English vowels (/i/, $\left.|I /,| e^{I} /,|\varepsilon|,|c e /|, o /,|\Lambda /,| \mathrm{m} /,|\mho /| u /,\right)$ by means of a task that required participants to repeat words spoken by a native speaker. L2 production ability significantly correlated with discrimination of L2, L2-L1, and L1 contrasts. Conversely, Kartushina and Frauenfelder (2014) found no relationship between L2 speech perception and production abilities. They tested 14 Spanish (L1)-French (L2) bilinguals with an L2 intermediate level, learning French for 4 years at school. L2 speech perception was measured in five-alternative forced-choice identification tasks involving French contrasts difficultly

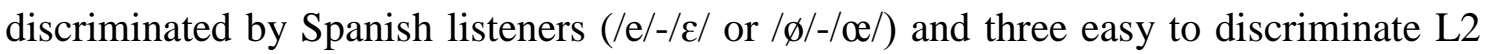
vowels $(/ \mathrm{i} /, / \mathrm{u} /, / \mathrm{y} /$ for the contrast /e/-/ $\varepsilon /$ or /o/, / //, /a/ for the contrast /ø/-/œ/). L2 speech production was measured by repetition of vowels spoken by a native speaker, similar to Flege et al. (1999), and a naming task with pictures. The participants' L2 perception and production abilities did not correlate. However, it was not reported if the correlations were calculated for each L2 production task separately or combined for both production tasks. This is important because each production task could involve different phonological processes: the repetition task might involve the imitation of the native speaker and therefore rely on sub-lexical processes (as in the identification task used by Flege et al., 1999), while the naming task might tap into phono-lexical processes required to map the corresponding phonemes to the selected lexical entry. An open question is therefore whether the strength of the relation between speech perception and production depends on the type of phonological process at play.

The hierarchical organization of phonological processes 
Leaving aside what composes the basic unit (acoustic features, articulatory gestures, or a combination of both), theoretical models conceptualize speech perception and production as a hierarchical organization of phonological processes (Fromkin, 1971; MarslenWilson \& Welsh, 1978; Dell, 1986; McClelland \& Elman, 1986; Levelt, 1989; Norris, 1994; Levelt et al., 1999; Hickok \& Poeppel, 2007). In speech perception models, one of the first processes in the hierarchy involves the recognition of phonemes (sub-lexical process), which in a subsequent step are used to access the words in the mental lexicon (phono-lexical process). For speech production, information follows the opposite direction: first a lexical item is selected that is then broken down into sub-lexical representations in order to articulate the word. This hierarchical structure has implications for L2 learning, since it implies that successful command of the phonemes at a sub-lexical level is necessary to accurately identify or produce a word. For example, the difficulties of Japanese learners of English in perceiving the difference between /l/ and /r/ (Miyawaki et al., 1975) results in problems when listening to words that only differ in this phoneme, such as "red" and "led" (Strange \& Dittmann, 1984).

The pattern of individual differences in early and late bilinguals follows the conceptualized hierarchy of phonological processes (Sebastian-Galles \& Baus, 2005; Díaz, Mitterer, Broersma, \& Sebastian-Galles, 2012). Sebastian-Galles and Baus (2005) tested 80 early Spanish (L1)-Catalan (L2) bilinguals in three tasks that tapped into different levels of the speech processing hierarchy. All the tasks involved the Catalan /e/-/ع/ contrast, which is difficult to discriminate for Spanish-dominant listeners because both Catalan phonemes are assimilated to the Spanish /e/ (Pallier et al., 1997; Bosch, SebastianGalles \& Soto-Faraco, 1999; Costa, \& Sebastian-Galles, 2000; Sebastian-Galles, Echeverría, \& Bosch, 2005). Two tasks assessed distinct types of sub-lexical processes. A categorization task along a seven step continuum of isolated, synthesized vowels 
ranging from $/ \mathrm{e} /$ to $/ \varepsilon /$ measured the processing of acoustic-phonemic information, and a gating task of naturally spoken words measured the identification of the critical phonemes /e/ and / / / in minimal word pairs. The co-articulation present in the words made phoneme identification more complex than in the categorization task where isolated vowels were presented. A lexical decision task assessed phono-lexical processes. In this task words and non-words were presented; the words included one of the two phonemes of the critical /e/ and / / / contrast and non-words were generated by replacing the critical vowel with the other vowel of the contrast. Comparing the performance of bilinguals to native Catalans, a high percentage of bilinguals were able to perform as well as Catalan natives in the categorization task (68.3\%), but less were able to do so in the gating task (46.6\%), and even less in the lexical decision task (18.3\%). At the individual level, the pattern of the results showed that good performance in the sub-lexical tasks was necessary for an accurate performance in the lexical task, in line with the hierarchical structure of the speech perception system proposed. However, perception of the difference between isolated phonemes did not ensure incorporation of the information in the lexical decision task.

In a preliminary analysis, Sebastian-Galles and Baus (2005) tested if early and highly proficient Spanish (L1)-Catalan (L2) bilinguals who differed maximally in their L2 perception skills also differed in their L2 production ability. The authors selected two groups of participants, one of which $(n=7)$, the so-called "good perceivers" (GP), performed consistently within the range of Catalan natives in the three L2 perception tasks described above (categorization, gating, and lexical decision tasks). The other group ( $\mathrm{n}=10)$, the so-called "poor perceivers" (PP), performed below the level of native Catalans' performance in all L2 perception tasks. L2 production accuracy of the two groups was measured in a picture-naming task, thus measuring phono-lexical processes, 
and compared to Catalan natives $(\mathrm{n}=10)$. Results of the preliminary analysis showed that both Catalan natives and GPs were rated to have a lower non-native accent compared to PPs. The data suggests that mastering L2 phono-lexical processes during speech perception results in the mastering of phono-lexical processes during production; however, the sample was too small to perform statistical analysis and further evidence is necessary to support this claim.

\section{Speech perception across participants' languages}

Another relevant characteristic of the organization of the speech perception system was revealed by an event-related potential (ERP) study on the sample studied by SebastianGalles and Baus (2005). Díaz et al. (2008) showed that speech perception abilities are correlated across listeners' languages (see also Díaz et al., 2016) by means of the Mismatch negativity $(\mathrm{MMN})$. The $\mathrm{MMN}$ is an electrophysiological component related to auditory discrimination ability that is elicited when a deviant stimuli is presented among repeated (standard) stimuli (Näätänen, Paavilainen, Rinne, \& Alho, 2007). Díaz et al. (2008) measured the MMN amplitude for two phoneme contrasts (Spanish native /o-e/ and Finnish unknown /o-ö/) and three auditory tone conditions (frequency, duration, and pattern) and tested whether the phoneme and tone discrimination sensitivity was related to L2 perception skills. Two groups of early Spanish (L1)-Catalan (L2) good (GP) and poor perceivers (PP) were selected from the sample tested in Sebastian-Galles and Baus (2005). The two participant groups differed maximally in their speech perception skills at both the sub-lexical and phono-lexical level: GPs performed as well as Catalan natives in all L2 perception tasks, and PPs performed below Catalan natives in all L2 perception tasks. Results showed larger MMN to speech stimuli (native and unknown), regardless of phoneme familiarity, for GPs compared to PPs, while the two groups showed similar MMNs in the tone conditions (frequency, duration, and pattern). 
The results suggest that there is a single phonemic ability, and variability in this ability does not depend on general auditory processing. Thus, high variability in L1 perception skills can be captured measuring electrophysiological responses (Díaz et al., 2008), which might be a valuable tool for studying the correlation between speech perception and production ability across the participants' languages.

\section{Speech perception across sensory modalities}

One aspect that is not accounted for by current models of speech perception (with the exception of the PACT, Schwartz et al., 2012) is the relevance of visual articulatory cues for speech perception. Several studies have shown that speech processing does not only rely on auditory but also on visual speech information. For instance, the McGurk effect (McGurk \& MacDonald, 1976) showed that when /pa/ is presented aurally simultaneously with $/ \mathrm{ka} /$ in the visual modality, participants report hearing $/ \mathrm{ta} /$, meaning they perceived none of the presented unisensory syllables, but rather a fusion of both. More recent research has shown that congruent visual speech enhances speech comprehension (Sumby, 1954; Arnold \& Hill, 2001; Navarra \& Soto-Faraco, 2007; Ross, Saint-Amour, Leavitt, Javitt, \& Foxe, 2007). This beneficial effect of visual speech has being attributed to the temporal precedence of visual cues which might provide the speech system with predictions in the form of constraints about the incoming phonemes (SánchezGarcía, Alsius, Enns, \& Soto-Faraco, 2011; Sánchez-García, Enns, \& Soto-Faraco, 2013; Wassenhove, Grant, \& Poeppel, 2005). Sánchez-García et al. (2011 and 2013) presented participants with silent videos of a speaker articulating speech, followed by an audiovisual video of the same speaker articulating speech. The linguistic message of the visual-only video would either continue in the subsequent video in the visual, auditory, or both sensory modalities (continuous conditions), or not continue (discontinuous conditions). Participants were asked to evaluate in the second audiovisual video whether the 
audio and the visual speech conveyed the same information. The authors found faster judgments when the visual part continued into only the visual, only the auditory, or both sensory modalities of the following audio-visual part. The study showed that the visual gesture can be a useful cue to facilitate speech processing by generating predictions of the forthcoming signal.

\section{The present study}

In the present study we aimed to study the relation between speech perception and production. Here we defined speech perception in a broader manner than in previous studies: an ability that involves different phonological processes (sub-lexical and phonolexical), languages (L1 and L2), and sensory modalities (auditory and visual). As such we assessed a variety of perception and production measures in early and highly proficient Spanish (L1)-Catalan (L2) bilinguals. To measure participants' speech perception ability we used behavioral tasks evaluating the learning of a difficult L2 contrast, the Catalan $/ \mathrm{e} /-/ \varepsilon /$, that tapped into sub-lexical and phono-lexical processes (SebastianGalles \& Baus, 2005), the electrophysiological response MMN measuring discrimination sensitivity of native and unknown phonemes (Díaz et al., 2008 and 2016), and behavioral and event-related potential (ERP) responses to native visual speech processing in a cross-modal prediction task (Sánchez-García et al., 2013). In the cross-modal prediction task we assessed participants' ability to use visual speech to predict auditory speech. For this purpose we tested the transfer of visual predictions to auditory processing, the cross-modal continuous mismatching condition, and compared it to a control condition in which no transfer of the visual gesture took place, the discontinuous mismatching condition, as in Sánchez-García et al. (2011 and 2013). We recorded additional ERPs on top of the behavioral responses, as previous ERP studies have shown reduced amplitude of the N1 and P2 components when auditory speech can be predicted 
based on preceding visual speech (Besle, Bertrand, \& Giard, 2009; Wassenhove et al., 2005).

Production abilities were only measured for L2 sounds with the aim of capturing large variability among the participants. We did not measure participants' native language production as natives perform at ceiling and this measure would lead to reduced variability. We measured production skills for L2-specific vowels and consonants with the naming task used in Sebastian-Galles and Baus, (2005), but we evaluated participant production separately for vowels and consonants, which differed from the original study. We aimed to investigate whether the relation between perception and production in the present sample was specific to vowels, to the type of speech sounds used to assess participants L2 perception abilities or whether the relation is present for all speech sounds. The acoustic and articulatory properties of vowels and consonants are very different and might show distinct strengths in the relation between perception and production. Vowels are steady-state sounds produced with a relatively open vocal tract and have a high intensity. Conversely, consonants are fast-transitions produced by constricting the vocal tract and are of low intensity. At the theoretical level, it has been claimed that vowels and consonants play different functional roles in language. It has been suggested that vowels carry primarily grammatical information whereas consonants provide information about words (Nespor, Peña, \& Mehler, 2003; Bonatti, Nespor, Peña, \& Mehler, 2005). For instance, word learning has been found to preferentially rely on the transitional probabilities of consonants as compared to vowels (Bonatti et al., 2005). In addition, in contrast with Sebastian-Galles and Baus (2005), we tested the full L2 perception proficiency distribution rather than the extreme ends of the distribution (i.e., GPs and PPs). 
Finally, non-linguistic perception and production skills were assessed to investigate whether the relation between speech perception and production is influenced by non-linguistic capabilities. We accessed non-linguistic perception abilities by means of the MMN to tones (Díaz et al., 2008 and 2016), and non-linguistic production skills by a computerized drawing task. Like speech production, drawing relies on the acquisition of very precise movements. Some researchers proposed a link between speech processing and sensory-motor abilities based on the observation that dyslexics, who have a phonological disability that impairs reading and spelling, frequently show deficits in learning sensory-motor skills and sensory-motor abilities in general (Ramus, Pidgeon, \& Frith, 2003; Ullman, 2004; Vicari et al., 2005; Hedenius et al., 2013). However, studies have shown that not all dyslexics present general-motor issues (Kelly, Griffiths, \& Frith, 2002; Ramus, 2003; Gabay, Schiff, \& Vakil, 2012).

To investigate how all these speech abilities relate, we ran an exploratory factor analysis that allowed us to investigate complex relations between several variables by grouping related measures by shared factors without prior information about the relationship between variables. Each factor represents a construct that is defined by the variables grouped in the given factor. In addition, within the factors, each variable is assigned a load that indicates the contribution of the measure to the factor. High loads are interpreted as stronger relations between the variable and the given construct represented by the factor. If speech perception and production are tightly related (Fowler, 1986; Liberman \& Mattingly, 1985, Best, 1995; Best \& Tyler, 2007; Bever \& Poeppel, 2010; Schwartz et al., 2012; Skipper et al., 2017), we expect that the two abilities will be grouped as a single factor. On the contrary, if speech perception and production are two separate abilities (Flege, 1995; Hickok \& Poeppel, 2007; Marslen-Wilson \& Welsh, 1978; McClelland \& Elman, 1986; Norris, 1994; Flege, 1995; Hickok \& Poeppel, 2007; 
Hickok et al., 2011), we should find separate factors encompassing the measures for each type of linguistic process. In addition, we expect that the specific grouping of the measures and their loads within the factors will shed light on how different aspects of speech perception and production are hierarchically organized. Finally, if linguistic abilities do not depend on non-linguistic ones, we expect no contribution of the nonlinguistic measures in the speech factors. The results will then be relevant to refute or accept theoretical accounts of the relation between speech perception and production and will help to discern the cause of the inconsistent results in the correlation between the two speech processes in L2 studies.

\section{Methods}

\section{Procedure}

The experiments were run over two sessions on separate days. Table 1 [Table 1 near here] gives an overview of the processes and tasks measured in the two sessions and the participants tested and included in the final sample for the factor analysis. All participants completed the first session that lasted approximately one hour. The first session included a Catalan production task (picture-naming) and three behavioral speech perception tasks that measured the auditory discrimination accuracy of the Catalan contrast /e/-ع/: categorization, gating, and lexical decision tasks (same as in Sebastian-Galles \& Baus, 2005). This session allowed us to compare Catalan natives' performances with those of Spanish dominant bilinguals. By comparing the two populations, we aimed to confirm whether the behavioral measures provided enough individual variability, from good to poor performance, to include the measures in the factor analysis. Control trials in the lexical decision task were used to ensure that the Spanish dominant participants had a high level of proficiency in their L2 and participants scoring below an A' of 0.9 (corresponding to 80\%) were excluded from the study (7 participants). If Spanish domi- 
nant bilinguals passed the control trials of the lexical decision task, they were invited for the second session, in which no Catalan native was tested. The second session lasted approximately 2 hours and involved the recording of ERPs to measure audio-visual prediction ability (by means of a cross-modal speech prediction task), phoneme and nonlinguistic auditory discrimination sensitivity (by means of the MMN), and sensorymotor skills (by means of a drawing task).

All experiments were programmed using the Psychtoolbox (3.0.8 or 3.0.10, Brainard, 1997; Pelli, 1997) running on MATLAB ® (7.11.0, R2010b, The MathWorks Inc, Natick, MA), except for the audio-visual prediction task that was presented with EPrime (2.0.10.182) and the sensory-motor task for which an existing game was used. The behavioral experiments of the first session were carried out in a sound attenuated room. During the L2 perception task, the audio was played through headphones (Sennheiser PC161). The headphones had an integrated microphone to additionally record the audio for the $\mathrm{L} 2$ production task (at $16 \mathrm{kHz}$ ). The ERP experiments were carried out in an electrically shielded room. For the ERP experiments the audio was played through two loudspeakers (Creative T-20) located at each side of the screen. The participants were placed at a distance of $60 \mathrm{~cm}$ from the screen. ERPs were recorded by means of 31 electrodes mounted in an electrocap (Electro-Cap International). Additional single electrodes were used to record from the left and right mastoids (LM and RM) and to measure vertical and horizontal eye movements (placed on the infraorbital ridge and the outer canthus of the right eye). For the audio-visual prediction task, the LM was used as the reference. For the MMN, an electrode placed on the tip of the nose served as the reference. Electrode impedances were kept below $5 \mathrm{kOhm}$ and the electroencephalogram (EEG) was recorded with a sampling rate of $500 \mathrm{~Hz}$. For all tasks, participants were trained before starting the experiment and feedback was provided. The behavioral 
data was analyzed with MATLAB ${ }^{\circledR}(8 \cdot 2.0 .701$, R2013b, The MathWorks Inc, Natick, MA). EEG data was pre-processed using BrainVision Analyzer (2.0.4.368, Brain Products) and the segmented data was then transferred to EEGLAB (v12.0.2.5b, Delorme \& Makeig, 2004) running on MATLAB® $(8.2 .0 .701$, R2013b, The MathWorks Inc, Natick, MA). All testing took place at the Neuroscience laboratories (Center for Brain and Cognition, Pompeu Fabra University, Barcelona, Spain).

Session 1: L2 speech perception and production tasks

\section{Participants}

One hundred twelve Spanish dominant (Spanish L1, Catalan L2) bilinguals were tested on their L2, i.e., Catalan, speech skills. In addition, 20 Catalan natives performed the tasks. Their data served to establish native-like performance in the tasks but was not included in the factor analysis. The participants were selected through a language questionnaire based on the following criteria: (1) They were born and raised in Barcelona Metropolitan area in Catalonia, ensuring that they were exposed to the same Catalan dialect, and, hence, to the Catalan phonemic contrast of interest: the /e/-E/ contrast. (2) For the Catalan natives, parents and grandparents were born in Catalonia and Catalan was their dominant language. For the Spanish dominant bilinguals, parents and grandparents had Spanish as the dominant language and did not come from regions of Spain where the experimental Catalan contrast /e/- $\varepsilon /$ is used (some dialects in Spain, in particular the regions of eastern Andalusia and surrounding, possess the /e/-/ع/contrast). (3) Only their L1 was used at home with their family and contact with their L2 was infrequent until around 3 years, when they started kindergarten. (4) From kindergarten on, education was bilingual and participants reported themselves to be highly proficient in both Spanish and Catalan. (5) They self-reported not having or had hearing or neurolog- 
ical problems. (6) Participants were all university students or completed their university degree recently, recruited through laboratories of the Pompeu Fabra University (the Neuroscience laboratory and the LeeX, Laboratori d'Economia Experimental), posters in the campuses of the university and announcements in the private online student area of the Pompeu Fabra University. The study was in accordance with the declaration of Helsinki and ethically approved by local authorities. Participants signed the corresponding written informed consent and were paid for their participation (10€/hour).

\section{Tasks}

Categorization task. The categorization task was the same as described in Pallier et al. (1997). Participants were presented with the same synthesized seven step continuum between the Catalan vowels /e/ and / / / used in the original study. In 63 trials ( 9 repetitions of each of the 7 steps in the continuum), participants listened to one stimuli and had to indicate with a button press ( 1 and 2 keys on the number pad) if the vowel they listened to appeared as the first vowel in the Catalan word "Pere" (/pere/, meaning "Pe-

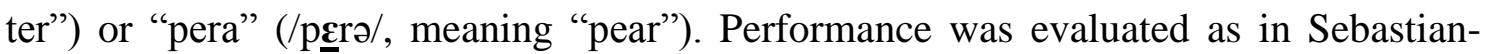
Galles and Baus (2005), the number of /e/ responses were averaged separately for the stimulus steps 1 and 2, which corresponded to the /e/-like stimuli, and to the steps 6 and 7 , corresponding to the $/ \varepsilon /$-like stimuli, and the latter was subtracted from the former. The subtraction score was transformed to absolute value (negative scores would indicate a switch in category which was not taken into account). The "discrimination scores" ranged from 1 , perfect performance, to 0 , low performance.

Gating task. The gating task has been described in Sebastian-Galles and Soto-Faraco (1999), with modifications mentioned in Sebastian-Galles and Baus (2005). In the task, four minimal Catalan word pairs, which only differed in the vowel /e/ and / $/$ / (such as 
/perr/ and /prarə/) and spoken by a native speaker, were presented to the participants. The task consisted of 16 trials ( 2 repetitions of each of the 2 words in the 4 minimal pairs) in which incremental segments of a word ("gates") were presented until the whole word was presented. The initial segment included the beginning of the word until the critical vowel started and then the length of the word segment incremented in $20 \mathrm{~ms}$ for 10 steps, until the whole word was presented in the last step. In each step, participants reported by button presses ( 1 and 2 keys on the number pad) which of two words from the minimal pair (that were printed on the screen) they thought they had listened to and how confident they were about the rating (from 0: unsure to 9: very sure). To facilitate the task, before each gating trial started, both possible words were written on the screen and each of the two words was played (marking the word that was played) so participants could associate the written word and audio stimulus. Participants could replay the words up to 6 times. Performance was evaluated as in Sebastian-Galles and Baus (2005) by calculating the number of correct responses on the last step of each gating trial, i.e., when the whole word was presented. Note that the present evaluation of the gating task measured word recognition rather than the point at which the words were recognized, which is the classic use for the gating task.

Lexical decision task. During the lexical decision task, described in Sebastian-Galles et al. (2005), participants were presented with Catalan words and non-words recorded by a native Catalan speaker. The experimental non-words were created by replacing the vowels /e/ and / / / by the other member of the phoneme contrast in the Catalan words

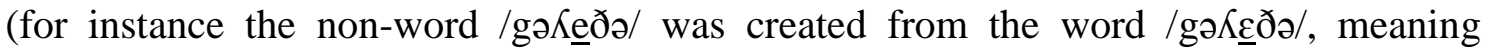
"bucket"). There were 66 words and 66 non-words, spread over two lists so that participants only listened to either the word or the non-word of the same word pair. Stimuli lists were counterbalanced across participants. Furthermore 40 control words and 40 
control non-words were included. For the control non-words, vowels that exist both in Spanish and Catalan were replaced by other vowels (for instance the non-word /Kənsal// was created from the word / əəns $\mathrm{l} /$, meaning "bed sheet"). Control non-words were created from words not present as control words and all participants listened to all control stimuli. Participants responded with button presses (1 and 2 keys on the number pad) if the stimulus they just had listened to was a Catalan word or a non-word. Correct responses were averaged separately for the $/ \mathrm{e} /, / \varepsilon /$, and control stimuli and transformed to A' scores. To calculate a common score for both /e/ and $/ \varepsilon /$ stimuli for the factor analysis, they were transformed to z-scores based on the performance of the Catalan natives and then averaged (see Dupoux, Peperkamp, \& Sebastian-Galles, 2010, for the same approach).

L2 speech production. A picture-naming task was used, consisting of the same sixty pictures as described in Sebastian-Galles and Baus (2005). Pictures presented frequent Catalan words, such as animals, fruits, and colors. Except for the pictures of colors, they were black and white drawings, presented in the middle of a white square of approximately $21 \times 11 \mathrm{~cm}$ at the center of a black screen. Each word included one or more Catalan-specific vowels and/or consonants (i.e. not existing in Spanish). The frequency of appearance of each vowel in the set of 60 pictures were: $16 / \varepsilon /, 17 / \mathrm{e} /, 12$ /Ј/, 7 /o/, and for the consonants: $6 / \mathrm{z} /, 17 / \mathrm{s} /, 5 / \mathrm{J} /, 4 / \mathrm{z} /, 1 / \mathrm{t} /, 1 / \mathrm{tz} /$. Before the recording, participants named all pictures once to ensure that they produced the intended words that contained the phonemes of interest (e.g. the word "house" for the picture of a building). Participants were given a book with all pictures and named them one by one. In case they did not find the intended word, the experimenter showed them the written word. Afterwards, the pictures were presented in a random order on the computer screen. Participants named each word and once finished, continued to the next word by pressing 
the space bar. They had a maximum of one minute to respond. For the evaluation of the phonemes, audio files were created to contain one word (starting approximately $20 \mathrm{~ms}$ before the audio). Three independent judges with training in Phonetics, evaluated each of the Catalan-specific phonemes in the participants' productions in a 1 to 5 scale $(1=$ strong Spanish accent, definitively not native; 5 = absolutely no Spanish accent, definitively native). Three lists with a different order of the speakers were created including the productions of Catalan natives spread equally throughout the list. The ratings were averaged across the different occasions and raters resulting in one score for each participant and each phoneme. For the factor analysis, the ratings were then averaged for the vowels and consonants.

Session 2: Electrophysiological studies - audio-visual prediction ability, phoneme, and non-linguistic auditory discrimination sensitivity (MMN) - and sensory-motor ability

\section{Participants}

61 Spanish dominant bilinguals who took part in the first session were tested in the second session. Only participants who passed the control trials of the lexical decision task in the first session and who self reported to be right handed were included. Handedness was confirmed with The Edinburgh Handedness Inventory (Oldfield, 1971) and one participant was excluded in the EEG parts only because of an ambi-lateral score (29 on a scale from 10, strongly right-handed, to 50, strongly left-handed).

\section{Tasks}

Audio-visual prediction. The Spanish version of the cross-modal prediction task from Sánchez-García et al. (2013) was used and adapted for EEG recordings. A trial consisted of the presentation of a silent video of a male speaker saying the initial portion of a sentence that was followed by an audiovisual (AV) video of the same speaker articulat- 
ing the final portion of the same or a different sentence. Thus, in isolation, the visual and AV videos provided meaningless phrases. The participants' task was to judge whether the auditory and visual speech present in the AV video matched or not. The initial silent video served to investigate whether participants could benefit from previous agreeing visual speech information to perform the matching task. The sentences used in the experiment were semantically neutral (e.g. "the man was known as the funniest comedian worldwide") and, hence, the linguistic message provided by the silent videos did not favor any specific continuation.

Five experimental conditions were created by combining the factor "Continuity", referring to the continuity of the linguistic content from the first silent video into the second AV video, and the factor "Match", referring to the match of the linguistic content in the audio and visual domains of the AV video. The "Continuity" factor had 3 levels: continuity of the sentence presented in the silent video (i) into the visual modality of the AV video (intramodal continuous target), (ii) into the auditory modality of the AV video (cross-modal continuous target), or (iii) no continuation in any sensory modality of the AV video (discontinuous target). For the intramodal continuous and discontinuous targets there were mismatching and matching AV videos. For the crossmodal continuous targets only mismatching AV videos were used because the matching ones would be the same as those for the intramodal continous matching AV videos in which the sentence in the silent video continued into both the auditory and visual domains of the AV videos to create an AV matching.

In the factor analysis we only included the data from the cross-modal continuous mismatching condition because it assessed whether participants used the visual speech cues of the silent video to predict the auditory speech of the AV videos. Following Sánchez-García et al. (2013) we tested if participants could benefit from the continuity 
of the visual cues into the auditory modality by comparing the cross-modal continuous mismatching with the discontinuous mismatching condition. The two conditions we compared to assess whether participants used visual speech to predict auditory speech (cross-modal continuous mismatching and discontinuous mismatching conditions) involved splicing the silent and AV videos which ensured no differences in participants' attention at the splice point.

The initial silent videos varied in duration $(1,600,1,800,2,000$ or $2,200 \mathrm{~ms})$. During the silent videos a tone of $300 \mathrm{~Hz}$ and $120 \mathrm{~ms}$ in duration was rhythmically presented every $200 \mathrm{~ms}$ with the aim of maintaining alertness to the auditory information though the trial. Immediately after the offset of the initial silent video, the AV video of the same male speaker speaking was presented for $800 \mathrm{~ms}$. Participants answered if the audio and video in the AV video (when speech started) matched or mismatched by pressing the corresponding key on a mouse ("match": middle finger, "mismatch": index finger). Participants had 1,800 $\mathrm{ms}$ to answer and were instructed to answer as fast and accurately as possible. The response was followed by a blank screen $(1,000 \mathrm{~ms})$, an interval in which an instruction allowing blinking was printed on the screen $(2,000 \mathrm{~ms})$, and a red fixation point that indicated the start of the next trial $(500 \mathrm{~ms})$. A total of 200 trials were used to present 40 different sentences for each of the 5 experimental conditions. Trials were spread over 8 blocks. To control for the laterality of motor responses, each participant switched their response hand every two blocks, resulting in half of the trials responding with each hand, with the starting hand counterbalanced across groups. Overall, the only differences between Sánchez-García et al. (2013) and the present EEG version of their task were: (i) participants were asked not to move and blink during the experimental trials, (ii) after the participants' response we provided additional time to blink, and (iii) to keep the response-related motor EEG signals as similar as possible 
across participants we counterbalance within participants the response hand and we did not counterbalance the response finger between participants.

For each participant, mean accuracy and median reaction time (RT) were calculated for the cross-modal continuous mismatching and the discontinuous mismatching conditions. As in Sánchez-García et al. (2013), participants scoring below 65\% (average of all conditions) were removed from the analysis (14 participants). RT was calculated only on correct trials, and trials exceeding 2 standard deviations from the mean for a given participant and condition were excluded. The EEG was band-pass filtered between 0.1 and $50 \mathrm{~Hz}$ (slope: $12 \mathrm{~dB} / \mathrm{oct}$ ) and a notch filter was set at $50 \mathrm{~Hz}$. The EEG data (referenced online to LM) was re-referenced offline to the RM. Eye movements were corrected using the ICA ocular correction and segments with artifacts were rejected. EEG data from 3 participants was rejected due to 15 or less out of 40 segments in one condition. The data was segmented into epochs of $-100 \mathrm{~ms}$ pre-stimulus to $500 \mathrm{~ms}$ post-stimulus time-locked to the onset of the AV video only for correct trials. Segments were baseline corrected, the DC detrend was applied, and they were averaged for each participant and condition separately. The N1 and P2 amplitude for each participant was then calculated as the mean amplitude in a $50 \mathrm{~ms}$ interval centered at the peak $(\mathrm{N} 1$ : most negative peak within 100-200 ms, P2: most positive peak within 150-250 ms) in the grandaverages at electrode $\mathrm{Cz}$. To facilitate the interpretability of the relations between the tasks, the polarity of the N1 amplitude values was reversed for the factor analysis so that more positive values corresponded to higher N1 amplitudes.

Mismatch negativity (MMN). We used a shortened version of Díaz et al. (2008). MMNs were recorded for two phonemes conditions, native and unknown, and two acoustic tone (non-linguistic) conditions, duration and frequency. Each condition was presented in a separate experimental block in which the stimuli were presented following an oddball 
paradigm. For both phoneme conditions, the standard was the synthesized native vowel $/ \mathrm{o} /$ that varied in the second formant frequency $(\mathrm{F} 2)$ from the deviants, the native vowel /e/ in the native phoneme condition and the unknown Finnish vowel /ö/ in the unknown phoneme condition (F2 values: /o/: $851 \mathrm{~Hz}, / \mathrm{e} /:$ 1,940 Hz, /ö/: 1,533 Hz, all 200ms long, from Näätänen et al., 1997, and used in Díaz et al., 2008, for Spanish participants). For the duration condition two pure tones of $1,000 \mathrm{~Hz}$ were used: The duration standard was $200 \mathrm{~ms}$ long and the deviant was $40 \mathrm{~ms}$ long. For the frequency condition two pure tones of $50 \mathrm{~ms}$ length were used: the frequency standard was $1,000 \mathrm{~Hz}$ and the deviant was $1,090 \mathrm{~Hz}$. Each tone deviant corresponded to the largest deviations from the standards in Díaz et al. (2008). Each condition was presented in a different block with 400 standards and 100 deviants giving a presentation probability of 0.2 for the deviant stimulus.

EEG data was analyzed as in Díaz et al. (2008). The EEG was band-pass filtered between 0.1 and $30 \mathrm{~Hz}$ (slope: $12 \mathrm{~dB} / \mathrm{oct}$ ) and a notch filter was set at $50 \mathrm{~Hz}$. Eye movements were corrected using the ICA ocular correction and segments with artifacts were rejected. The data was segmented into epochs of $-100 \mathrm{~ms}$ pre stimulus to $500 \mathrm{~ms}$ post stimulus. Segments were baseline corrected and the DC detrend was applied. Averages for the standards and deviants for each condition were calculated. Difference waves were computed for each participant and condition by subtracting the average ERP to the standard from the average ERP to the deviant. The MMN amplitude for each participant and condition was calculated as the average amplitude in a $40 \mathrm{~ms}$ interval centered at the peak (most negative peak within 100-200 ms post-stimulus onset) in the difference waves at electrode Cz. To facilitate interpretability of the relations between tasks, the polarity of the MMN amplitude values was reversed so that more positive MMN values corresponded to better discrimination ability. 
Sensory-motor task. For the sensory-motor task we used the game "Neon Mania" (Vivid Games S.A., http://www.vividgames.com/games/Neon-Mania_543.html) on an iPad. In the game, participants drew eight different shapes (sun, flower, puzzle piece, bear, hippopotamus, octopus, a geometrical figure of three zigzag lines creating a triangle in the center, and a figure of zigzag lines creating a circle). Figures and an example trial are represented in Figure A1 in the appendix. To draw the figures, participants placed their finger on a star that appeared at the beginning of the shapes' contour line and dragged the star through the entire shapes' contour, coloring it. The score in the game was based on speed and accuracy in the drawing. Each small subpart of a line gave a score depending on the speed that it was drawn in, with higher speed giving higher scores. However, accuracy was also important. If a line was drawn too inaccurately, meaning that the finger went out of the line, the star got stuck in the place where the finger went out of the line and participants had to start again from this part, thereby losing the speed that they had build up during the drawing. If the figure consisted of more than one line, the next line could be drawn after the previous one was completed. The order of the lines to be drawn was fixed and figures with more than one line had "multipliers" applied to the lines. For example, if the second line was started within five seconds before finishing the first line, the scores for each subpart of this second line were multiplied by two. In the case of three lines, the scores for each subpart of the third line were multiplied by three, etc. In the experiment, each shape was drawn three times in a row and participants were instructed to draw as fast and accurately as possible. For the analysis, the scores for each shape were first standardized using z-scores (because lines varied in length, scores for the different figures were very different). Previous to the experimental trials, participants practiced the task by drawing one figure (an ice cream) two times. For each participant, two scores were then calculated: an overall score (averaging the 
standardized scores for each shape and try) and a learning score (subtracting the first tries of all figures from the last tries of all figures).

\section{Factor analysis}

\section{Final sample}

For the factor analysis, not all participants had data available for each task. Specifically, some participants did not want to participate in the second session, did not reach $65 \%$ correct responses or did not have enough EEG segments in the audio-visual prediction task, and not all participants had L2 speech production ratings available. For the factor analysis, participants were selected who had data available for all the L2 speech perceptions tasks (1st session) and, at least, one other task with the aim of including the maximum number of participants in the analysis. The sample sizes for each task can be found in Table 1.

\section{Variables}

A total of 15 variables were included (see Table 1): categorization task, gating task, lexical decision task (LDT), speech production of vowels and consonants, audio-visual prediction measures accuracy, RT, N1, and P2, MMN amplitudes for the native phoneme, unknown phoneme, frequency, and duration conditions, and the sensory-motor task with the total and learning scores.

\section{Analysis}

SPSS was used for the analysis. First, the number of optimal factors was computed using parallel analysis available from the R-Menu v2.0 (Courtney, 2013). In parallel analysis, the correlation matrix used for the factor analysis is randomized and eigenvalues for the randomized matrix are calculated. Eigenvalues measure the variance of the vari- 
ables included in a given factor. Those factors with eigenvalues greater than the ones obtained from the randomized matrix are retained. In other words, only factors that can explain more variance than a random matrix are selected (Courtney, 2013). Principal axis factor analysis was then fitted to the correlation matrix of the data with the number of factors obtained from the parallel analysis. In order to maximize the number of participants for each combination of tasks, missing values were excluded pairwise (meaning that for each correlation of two tasks, data from all participants having data in these two tasks was used). The "varimax" rotation was used to optimize the factor analysis output. Only variables with values $>0.3$ or $<-0.3$ are reported in the results section.

\section{Results}

\section{Individual tasks}

Figure 1 and Table 2 [Figure 1 and Table 2 near here] show the results for the L2 speech perception tasks. In all tasks, Spanish dominant bilinguals, for whom the experimental language was their L2, performed overall below Catalan natives, for whom the experimental language was their L1, as indicated by the significant t-tests. Furthermore, Spanish dominant bilinguals varied widely in their L2 perception skills as indicated by the range of the measures in Table 2. Figure 2 and Table 3 [Figure 2 and Table 3 near here] show the grandaverage MMN for the phoneme and tone conditions and the individual variability at the peak. All four MMNs were significantly different from zero and Spanish dominant bilinguals showed variability for all four MMNs. Figure 3 and Table 4 [Figure 3 and Table 4 near here] show the behavioral and electrophysiological data for the audio-visual prediction task. Participants were more accurate in judging whether the audio and visual speech matched in the discontinuous mismatching than in the crossmodal continuous mismatching condition. No differences between the two conditions 
were found for the RT, N1, and P2 measured. Spanish dominant bilinguals showed individual variability for all measures in the cross-modal continuous mismatching condition as seen in the range of the measures in Table 4.

Figure 4 and Tables 5 [Figure 4 and Table 5 near here] show the results for the L2 speech production task. Spanish dominant bilinguals were less accurate that Catalan natives in their pronunciation of both Catalan vowels and Catalan consonants, and Spanish dominant bilinguals varied widely in their L2 production skills. Figure 5 and Table 6 [Figure 5 and Table 6 near here] show the results for the sensory-motor task. Spanish dominant bilinguals showed learning as indicated by the significant t-test and varied in both measures of the drawing task: the total and learning score.

Overall, the bilinguals showed large individual differences for all the assessed behavioral and ERP measures. The wide range of variability ensures that the tasks were sensitive at capturing the individual variability necessary to perform the factor analysis.

\section{Factor analysis results}

Figure 6 [Figure 6 near here] shows the results for the factor analysis presenting factor loadings above 0.3 and below -0.3 . Table 7 displays the one-tailed Pearson correlations used by Factor analysis to find structure in the relationship among variables. Parallel analysis gave 4 factors as the optimal solution. In total over the four factors, $48.449 \%$ of variance was explained, spread over the first (22.487\%), second (10.786\%), third (7.688\%), and fourth (7.488\%) factors. Factor 1 included all L2 speech perception tasks (categorization, gating, and lexical decision) with loadings higher than 0.5, the MMN for the native phoneme with a loading higher than 0.3 and all measures for the L2 speech production task (vowels and consonants) with loadings higher than 0.85. Factor 2 included all MMNs (native, unknown, frequency, and duration) with loadings higher 
than 0.4 , the $\mathrm{N} 1$ for the audio-visual prediction task with a loading higher than 0.45 , and the L2 vowel production with a loading higher than 0.3 . Factor 3 included all measures for the audio-visual prediction task (accuracy, RT, N1, and P2) with loadings higher or lower than 0.3 or -0.3 respectively. Finally, factor 4 included the RT from the audiovisual prediction task with a loading higher than 0.6 and all sensory-motor ability measures (total and learning scores) with loadings higher or lower than 0.6 or -0.4 respectively.

\section{Discussion}

In this study we investigated the characteristics of the relationship between speech perception and production. To this aim we administered a battery of tasks to early and highly proficient bilinguals. We measured L2 speech perception and speech production capabilities across phonological processes, namely sub-lexical and phono-lexical, to investigate how the two abilities relate along the hierarchy of phoneme processes. Other speech perception abilities were assessed such as phoneme discrimination abilities for native and unknown vowels, to investigate the relation between speech perception and production across languages, and visual speech perception skills, to explore whether they relate to auditory speech perception and production. In addition to the linguistic measures, we measured general auditory and sensory-motor abilities by recording discrimination sensitivity to tones and a drawing task to reveal whether the relation of speech perception and production is influenced by non-linguistic skills. If speech production processes participate in speech perception (Liberman \& Mattingly, 1985; Fowler, 1986; Best, 1995; Best \& Tyler, 2007; Schwartz et al., 2012; Skipper et al., 2017), we expected to find a common factor for speech processes linking speech perception and production abilities across phonological processes, sensory modalities, and languages. Alternatively, following the separate view of speech perception and produc- 
tion processes (Flege, 1995; Hickok \& Poeppel, 2007; Hickok et al., 2011), we would expect speech perception and production abilities to be grouped into separate factors. In the following section we will first give an overview of the results for the individual tasks and then present the results of the factor analysis.

Results of the individual tasks showed that, as a group, the Spanish dominant bilinguals performed worse than Catalan natives in all the L2 perception tasks. At the individual level, the bilinguals showed a wide variability, from very good to very poor performances. These results are in line with previous studies (Sebastian-Galles \& Baus, 2005; Díaz et al., 2012). Regarding phonological and tone discrimination sensitivity, we measured overall reliable MMNs for the speech and tone conditions (native phoneme, unknown phoneme, frequency, and duration) that at the individual level showed wide variability, from positive to highly negative values, capturing differences between participants in phoneme and tone discrimination sensitivity. For the audio-visual prediction task, we expected to replicate Sánchez-García et al.'s (2011 and 2013) findings of faster RTs for the condition in which the visual linguistic context continued in the auditory signal during the audio-visual part, the cross-modal continuous mismatching condition, as compared to when the visual context did not continue in the audio-visual part, the discontinuous mismatching condition. Overall, we did not find differences in RTs between the two conditions. There were no global differences in the N1 and P2 amplitudes between both conditions, though participants showed poorer performance for the crossmodal continuous mismatching condition as compared to the discontinuous mismatching one. The lack of difference in RTs between the conditions could be due to a general slowing-down of the responses because of the higher demands when measuring ERPs (e.g., the need to control for blinking and movements). In line with this interpretation, RTs were slower in our study compared to the RTs measured by Sánchez-García et al. 
(2013) (cross-modal continuous mismatching condition: $1010 \mathrm{~ms}$ in this study, $904 \mathrm{~ms}$ in Sánchez-García et al., 2013; discontinuous mismatching condition: $998 \mathrm{~ms}$ in this study, 958 ms in Sánchez-García et al., 2013). Although we could not find evidence of the benefit of building cross-modal predictions in the audio-visual task, the large individual variability in the task nevertheless indicates that the Spanish dominant bilinguals varied in their ability to integrate the auditory and visual speech signals. Speech production ability of the Spanish dominant bilinguals was overall worse than for the native Catalans. Bilinguals showed a wide variability in production ability that ranged from very good to poor performance. Finally, the sensory-motor tasks showed that Spanishdominant bilinguals also varied in terms of non-linguistic motor performance. In summary, as expected, results for the individual measures showed a wide variability for the Spanish dominant bilinguals in all tasks. There were no ceiling or floor effects that would miss the assessment of relations between the variables and, hence, the use of factor analysis was permitted.

Results for the factor analysis revealed four factors. The first factor integrated speech perception and production measures across phonological processes (i.e. sublexical and phono-lexical), and languages (native and L2). The second factor included discrimination sensitivity for phonemes and tones, the N1 for the audio-visual prediction task, and L2 vowel production, measures which we will argue relate to auditory prediction. The third factor included all the measures recorded for the audio-visual speech task (accuracy, RT, N1, and P2 of the audio-visual task). The fourth factor grouped together the non-linguistic sensory motor task measures (total and learning scores from the drawing task) and the RT from the audio-visual prediction task. We interpret this factor as representing general motor abilities. 
A relationship between speech perception and production was captured by the first factor which included native and L2 speech perception at all hierarchical phonological processing levels (i.e., sub-lexical and phono-lexical), and L2 production for vowels and consonants. A common factor for speech perception and production along the hierarchy of phonological processes implies a tight relation between the two skills and fits well with the view that production contributes to speech perception (Fowler, 1986; Liberman \& Mattingly, 1985, Best, 1995; Best \& Tyler, 2007; Bever \& Poeppel, 2010; Schwartz et al., 2012; Skipper et al., 2017). However, based on the variables grouped in this factor, one cannot adjudicate between the theories that propose a causal role of production in speech perception. We cannot infer whether production processes provide the representations of speech perception, as advocated by motor theories (Best, 1995; Best \& Tyler, 2007; Fowler, 1986; Liberman \& Mattingly, 1985) and the PACT (Schwartz et al., 2012), or rather assist perception by providing constraints about the incoming speech input (Bever \& Poeppel, 2010; Skipper et al., 2017). While we interpret the first factor as suggesting a causal role of production in perception, other interpretations are plausible as well. All current proposals about the role of speech production in perception, both causal and epiphenomenal, accept to a certain degree influences of the production system on speech perception. The views that consider speech production as separate skill of perception propose that perception may need to recruit production processes under difficult listening situations (Hickok et al., 2011) or that accurate perception is a prerequisite for accurate production (Flege, 1995). Thus, while these views consider speech perception and production as separate processes, they would still expect some degree of correlation between the two skills. Taking into account only the L2 variables, the grouping of L2 perception and production skills into a common factor could be expected by proponents of production and perception as separate abilities (Flege, 1995; 
Hickok et al., 2011). One could argue that when the speech system is challenged, as in the case of L2 perception, there is a greater interaction between speech perception and production. For instance, within the acoustic view of speech perception, Hickok and Poeppel's (2007) Dual Stream model allows for interactions between speech perception and production in challenging listening situations. Although the Dual Stream model does not directly address L2 perception, it is conceivable that L2 perception may be one of these difficult situations because of the potential limited expertise of the L2 listener. In L2 contexts the listeners would therefore use articulatory information to achieve more efficient speech perception. Under these assumptions, a relation between L2 speech perception and L2 production would be expected by the model. However, the first factor also included the MMN in response to native vowel changes under normal listening conditions and no interaction between perception and production would be expected by this view. We interpret the present link between L1 perception and L2 production abilities as favoring the view that the role of the speech production system is not restricted to the perception of speech when the system is under challenging conditions.

Another interpretation of the common factor for speech perception and production that would not involve the assumption of the production system playing a causal role in perception can be derived from Flege's model on L2 learning (Flege, 1995). Flege's SLM argues that L2 production representations depend on the abstract representations created by the speech perception system. A relation between speech perception and production within a language is therefore clearly expected, but not one across languages given that L2 production representations do not depend on L1 phonological categories. However, the assumptions of the SLM of perception driving production skills could be accounted for if one considers native and L2 perception skills as a single ability. Previous studies have revealed that native perception skills relate to L2 perception 
(Díaz et al., 2008 and 2016). These studies showed that good and poor L2 perceivers differed in their electrophysiological discrimination ability of L1 and unknown phonemes, as indexed by the MMN. These findings open up the possibility that the present link between speech perception and production abilities across languages is grounded in the existence of a single speech perception ability that is similarly expressed in the processing of native and L2 phonemes.

Regarding the relation between speech perception and production within the hierarchy of phoneme processes, we found that speech perception and production measures were grouped together in the first factor for both sub-lexical and phonolexical processes. However, factor loadings were highest for the L2 tasks involving words such as the production task, the gating task, and the lexical decision task. Slightly lower factor loadings were found for the categorization task, in which participants listened to isolated phonemes. The differences in factor loadings suggest that the relation between speech perception and production is higher when the type of phoneme processes assessed for each speech ability taps into the same level of the processing hierarchy. Nevertheless, speech perception and production related at all levels of the hierarchy of phoneme processes, refuting our hypothesis that inconsistencies in the correlation strengths reported by previous studies were caused by the phoneme processes assessed (Flege et al., 1999; Kartushina \& Frauenfelder, 2014; Levy \& Law, 2010; Peperkamp \& Bouchon, 2011; Rallo Fabra \& Romero, 2012).

The first factor also showed a relation of speech production ability for both vowels and consonants with the speech perception tasks involving vowels. These findings show that within the speech production domain there is a similar ability for the production of both phoneme categories despite their differences in articulatory properties. The present link between perception and production is therefore not restricted to 
the specific phonemes evaluated in the speech perception tasks (i.e., vowels), but is rather present globally across vowels and consonants. Another relevant difference between vowels and consonants is the role they play in lexical and syntactic processing. Lexical processes are proposed to rely on the computation of consonant dependencies whereas syntactic processes rely on vowel distributions (Nespor et al., 2003; Bonatti et al., 2005). The similar loadings for the production of consonants and vowels suggest that this functional distinction might not be relevant for processes at lower levels of the language hierarchy, i.e., sub-lexical and phono-lexical processes.

Results of the factor analysis also showed that not all speech processes grouped together. Unexpectedly, all measures of the audio-visual task grouped as a single factor (the third one), apart from speech perception and production skills. This finding suggests that audio-visual speech integration ability is relatively independent from auditory speech perception or speech production abilities. This result is surprising since audiovisual speech integration involves the recognition of auditory speech and should be highly related to speech perception processes. We speculate that audio-visual integration of speech relies on general-domain cognitive mechanisms involved in fusing any type of sensory input across modalities to create multisensory percepts. Unfortunately, in the present study we did not measure audio-visual integration skills with nonlinguistic stimuli and we cannot validate or refute our speculation.

In the second factor different measures related to prediction processes were grouped. The highest loads corresponded to all MMN measurements and the N1 of the audiovisual task. Several studies consider the $\mathrm{MMN}$ as an index of prediction error (Wacongne, Changeux, \& Dehaene, 2012; Winkler \& Czigler, 2012). In the typical oddball paradigm, as the ones used to elicit the MMN, a standard sound is played repeatedly, resulting in high predictability of hearing another standard sound. The MMN 
is elicited when the expectation of hearing a standard is broken by a deviant being played. Likewise, prediction is at the core of the audio-visual prediction task. The aim of the task is to measure if predictions from the visual only signal can be created and used to facilitate the processing of the following audio signal (Sánchez-García et al., 2011 and 2013). The function attributed to the N1 by previous studies is to index the building of visual predictions about the timing of incoming auditory events for speech and non-speech stimuli (Besle et al., 2009; Stekelenburg \& Vroomen, 2007; Vroomen \& Stekelenburg, 2010). This view of the N1 fits well with the common factor for both speech and tone MMNs. L2 vowel production was also grouped in this factor. These results suggest that speech production relates to prediction processes. Such an interpretation would be in line with the view that that the speech production system provides restrictions about the number of potential incoming phonemes during speech perception (Bever \& Poeppel, 2010; Skipper et al., 2017). However, this interpretation should be considered with caution as it relies on our assumption that the construct captured by this factor is prediction and the other speech production measure (i.e., L2 consonant production variable) was not present in the factor.

We did not find a relation between speech perception and production skills with non-linguistic sensory-motor abilities. The fourth factor encompassed motor abilities, i.e., the two measures for the sensory-motor tasks (total score and learning) and the reaction time for the audio-visual prediction task. Although some studies found that dyslexics, who show a phonological deficit, are also impaired in sensory motor tasks (Hedenius et al., 2013; Ullman, 2004; Vicari et al., 2005), other studies failed to find this relationship (Gabay et al., 2012; Kelly et al., 2002; Ramus, 2003). Our results are in line with the latter studies. In our study, the separate factors for speech processes and sensory-motor skills suggest that the link between speech perception and production 
found in this study is speech-specific and not influenced by individual variability in sensory-motor skills. The current results support Díaz et al.'s (2008 and 2016) interpretation of a speech-specific origin of L2 perception and extend this result to L2 phoneme production. One difference in the present study regarding previous ones is that only the native MMN was present in the factor encompassing auditory speech skills and production, and not the unknown MMN. This might be due to a stronger difference between the groups of good and poor L2 perceivers for the MMN elicited by the native as compared to the unknown phoneme. In Díaz et al. (2008) the difference in the MMN amplitude between the GPs and PPs for the native phoneme was larger compared to the unknown phoneme; although this effect did not reach significance it suggests that L2 abilities relate more strongly to native skills than to the perception of unfamiliar phonemes.

Overall, the first factor encompassing speech perception and production abilities across languages and phonological processes seems to be congruent with the conceptualization of the production system being causally involved in speech perception (Best, 1995; Best \& Tyler, 2007; Fowler, 1986; Liberman \& Mattingly, 1985; Schwartz et al., 2012; Bever \& Poeppel, 2010; Skipper et al., 2017). However, the alternative explanation of production depending on perception (Flege, 1995) could also account for the overlapping variance found between speech perception and production abilities shown by the first factor. Because of its correlative nature, the present study does not allow for inferences about the directionality of the relationship among the variables, but it clearly indicates a tight interaction between the two speech abilities. Thus, although previous studies have shown inconsistent strength of the relationship between speech perception and production abilities in L2 learners (Flege et al., 1999; Kartushina \& Frauenfelder, 2014; Levy \& Law, 2010; Peperkamp \& Bouchon, 2011; Rallo Fabra \& Romero, 2012), 
in the current study we found evidence for a strong relation between speech perception and production.

Speech perception is a complex phenomenon. Traditionally it has been studied by analyzing how native listeners perform in separated tasks where only auditory stimuli are presented. Such an approach suffers from different limitations: first, performance in native speech perception is generally at ceiling. Second, speech processing involves the processing of multimodal information (visual as well as articulatory), and, third, this approach does not permit observation of how different subprocesses involved in speech perception relate to each other. In the present research we adopted a novel and comprehensive approach by testing the same participants in several speech and non-speech perception and production tasks in order to analyze how the different abilities relate to each other. Such tasks ranged from the perception of isolated phonemes to the integration of complex audiovisual sentences, including stimuli in the native and non-native languages of the participants. A relation between speech perception and production was present across participants' languages and phonological processes. The present results have provided new insights regarding the complexity of speech processing.

\section{References}

Arnold, P., \& Hill, F. (2001). Bisensory augmentation: a speechreading advantage when speech is clearly audible and intact. British Journal of Psychology, 92, 339-355. doi:10.1348/000712601162220

Besle, J., Bertrand, O., \& Giard, M. H. (2009). Electrophysiological (EEG, sEEG, MEG) evidence for multiple audiovisual interactions in the human auditory cortex. Hearing Research, 258, 143-151. doi:10.1016/j.heares.2009.06.016 
Best, C. T. (1995). A direct realist view of cross-language speech perception. In W. Strange (Ed.), Speech Perception and Linguistic Experience: Issues in CrossLanguage Research (pp. 171-204). Baltimore: York Press.

Best, C. T., \& Tyler, M. D. (2007). Nonnative and second-language speech perception: Commonalities and complementarities. In O.-S. Bohn \& M. J. Munro (Eds.), Language experience in second language speech learning: In honor of James Emil Flege (pp. 13-34). Amsterdam: John Benjamins Publishing Company.

Bever, T.G., \& Poeppel, D. (2010). Analysis by synthesis: A (re-) emerging program of research for language and vision. Biolinguistics, 4, 174-200.

Bonatti, L. L., Peña, M., Nespor, M., \& Mehler, J. (2005). Linguistic constraints on statistical computations: The role of consonants and vowels in continuous speech processing. Psychological Science, 16, 451-459. doi: 10.1111/j.09567976.2005.01556.x

Bosch, L., Costa, A., \& Sebastian-Galles, N. (2000). First and second language vowel perception in early bilinguals. European Journal of Cognitive Psychology, 12, 189-221. doi:10.1080/09541446.2000.10590222

Brainard, D. H. (1997). The Psychophysics Toolbox. Spatial Vision, 10, 433-436. doi:10.1163/156856897X00357

Caramazza, A., Miceli, G., Villa, G., \& Romani, C. (1987). The role of the Graphemic Buffer in spelling: evidence from a case of acquired dysgraphia. Cognition, 26, 5985. doi:10.1016/0010-0277(87)90014-X

Courtney, M. G. R. (2013). Determining the number of factors to retain in EFA : Using the SPSS R-Menu v2.0 to make more judicious estimations. Practical Assessment, Research \& Evaluation, 18, 1-14. 
D’Ausilio, A., Pulvermüller, F., Salmas, P., Bufalari, I., Begliomini, C., \& Fadiga, L. (2009). The motor somatotopy of speech perception. Current Biology, 19, 381385. doi:10.1016/j.cub.2009.01.017

Dell, G. S. (1986). A spreading-activation theory of retreival in sentence production. Psychological Review, 93, 283-321.

Delorme, A., \& Makeig, S. (2004). EEGLAB: an open source toolbox for analysis of single-trial EEG dynamics including independent component analysis. Journal of Neuroscience Methods, 134, 9-21. doi:10.1016/j.jneumeth.2003.10.009

di Pellegrino, G., Fadiga, L., Fogassi, L., Gallese, V., \& Rizzolatti, G. (1992). Understanding motor events: a neurophysiological study. Experimental Brain Research, 91, 176-180. doi:10.1007/BF00230027

Díaz, B., Baus, C., Escera, C., Costa, A., \& Sebastian-Galles, N. (2008). Brain potentials to native phoneme discrimination reveal the origin of individual differences in learning the sounds of a second language. Proceedings of the National Academy of Sciences of the United States of America, 105, 16083-16088. doi:10.1073/pnas.0805022105

Díaz, B., Mitterer, H., Broersma, M., Escera, C., \& Sebastian-Galles, N. (2016). Variability in L2 phonemic learning originates from speech-specific capabilities: An MMN study on late bilinguals. Bilingualism: Language and Cognition, 19, 955970. doi:10.1017/S1366728915000450

Díaz, B., Mitterer, H., Broersma, M., \& Sebastian-Galles, N. (2012). Individual differences in late bilinguals' L2 phonological processes: From acoustic-phonetic analysis to lexical access. Learning and Individual Differences, 22, 680-689. doi:10.1016/j.lindif.2012.05.005 
Dupoux, E., Peperkamp, S., \& Sebastian-Galles, N. (2010). Limits on bilingualism revisited: Stress “deafness” in simultaneous French-Spanish bilinguals. Cognition, 114, 266-275. doi:10.1016/j.cognition.2009.10.001

Fadiga, L., Craighero, L., Buccino, G., \& Rizzolatti, G. (2002). Speech listening specifically modulates the excitability of tongue muscles: a TMS study. European Journal of Neuroscience, 15, 399-402. doi:10.1046/j.0953-816x.2001.01874.x

Flege, J. E. (1995). Second Language Speech Learning: Theory, Findings, and Problems. In W. Strange (Ed.), Speech Perception and Linguistic Experience: Issues in Cross-Language Research (pp. 233-277). Baltimore: York Press.

Flege, J. E., MacKay, I. R., \& Meador, D. (1999). Native Italian speakers' perception and production of English vowels. The Journal of the Acoustical Society of America, 106, 2973-2987.

Fowler, C. A. (1986). An event approach to the study of speech perception from a direct-realist perspective. Journal of Phonetics, 14, 3-28.

Friederici, A. D. (2011). The brain basis of language processing: from structure to function. Physiological reviews, 91, 1357-1392. doi: 10.1152/physrev.00006.2011

Fromkin, V. A. (1971). The non-anomalous nature of anomalous utterances. Language, 47(1), 27-52. doi:10.2307/412187

Gabay, Y., Schiff, R., \& Vakil, E. (2012). Dissociation between the procedural learning of letter names and motor sequences in developmental dyslexia. Neuropsychologia, 50, 2435-2441. doi:10.1016/j.neuropsychologia.2012.06.014

Gazzaniga, M. S., Ivry, R. B., \& Mangun, G. R. (2002). Cognitive Neuroscience: The Biology of the Mind. New York, NY: W. W. Norton \& Company. 
Hedenius, M., Persson, J., Alm, P. a., Ullman, M. T., Howard, J. H., Howard, D. V., \& Jennische, M. (2013). Impaired implicit sequence learning in children with developmental dyslexia. Research in Developmental Disabilities, 34, 3924-3935. doi:10.1016/j.ridd.2013.08.014

Hickok, G., Houde, J., \& Rong, F. (2011). Sensorimotor integration in speech processing: computational basis and neural organization. Neuron, 69, 407-22. doi:10.1016/j.neuron.2011.01.019

Hickok, G., \& Poeppel, D. (2007). The cortical organization of speech processing. Nature Reviews. Neuroscience, 8, 393-402. doi:10.1038/nrn2113

Hillis, A. E., Rapp, B. C., \& Caramazza, A. (1999). When a rose is a rose in speech but a tulip in writing. Cortex, 35, 337-356. doi:10.1016/S0010-9452(08)70804-9

Ito, T., Tiede, M., \& Ostry, D. J. (2009). Somatosensory function in speech perception. Proceedings of the National Academy of Sciences of the United States of America, 106, 1245-1248. doi: 10.1073/pnas.0810063106

Kartushina, N., \& Frauenfelder, U. H. (2014). On the effects of L2 perception and of individual differences in L1 production on L2 pronunciation. Frontiers in Psychology, 5, 1-17. doi:10.3389/fpsyg.2014.01246

Kelly, S. W., Griffiths, S., \& Frith, U. (2002). Evidence for implicit sequence learning in dyslexia. Dyslexia, 8, 43-52. doi:10.1002/dys.208

Kittredge, A., \& Dell, G. S. (2016). Learning to speak by listening: Transfer of phonotactics from perception to production. Journal of Memory and Language, 89, 8-22. doi: 10.1016/j.jml.2015.08.001

Klatt, D. H. (1979). Speech perception: A model of acoustic-phonetic analysis and lexi- 
cal access. Journal of Phonetics, 7, 279-312.

Levelt, W. J. M. (1989). Speaking: from intention to articulation. Cambridge, Massachusetts: MIT Press.

Levelt, W. J. M., Roelofs, A., \& Meyer, A. S. (1999). A theory of lexical access in speech production. Behavioral and Brain Sciences, 22, 1-75. doi:10.1017/S0140525X99001776

Levy, E. S., \& Law, F. F. (2010). Production of French vowels by American-English learners of French: language experience, consonantal context, and the perceptionproduction relationship. The Journal of the Acoustical Society of America, 128, 1290-1305. doi:10.1121/1.3466879

Liberman, A. M., \& Mattingly, I. G. (1985). The motor theory of speech perception revised. Cognition, 21, 1-36. doi:10.1016/0010-0277(85)90021-6

Lotto, A., Hickok, G., \& Holt, L. (2009). Reflections on mirror neurons and speech perception. Trends in Cognitive Science, 13, 110e114. doi: 10.1016/j.tics.2008.11.008

Marslen-Wilson, W. D., \& Welsh, A. (1978). Processing Interactions Word Recognition and Lexical Access during in Continuous Speech. Cognitive Psychology, 10, 2963. doi:10.1016/0010-0285(78)90018-X

McClelland, J. L., \& Elman, J. L. (1986). The TRACE model of speech perception. Cognitive Psychology, 18, 1-86. doi:10.1016/0010-0285(86)90015-0

McGurk, H., \& MacDonald, J. (1976). Hearing Lips and Seeing Voices. Nature, 264, 746-748. doi:10.1038/264746a0

Miyawaki, K., Strange, W., Verbrugge, R., Liberman, A. M., Jenkins, J. J., \& Fujimura, O. (1975). An effect of Linguistic Experience: The discimination of [r] and [1] by 
native Speakers of Japanes and English. Perception \& Psychophysics, 18, 331340.

Möttönen, R., \& Watkins, K. E. (2009). Motor representations of articulators contribute to categorical perception of speech sounds. The Journal of Neuroscience, 29, 9819-9825. doi: 10.1523/JNEUROSCI.6018-08.2009

Näätänen, R., Lehtokoski, A., Lennes, M., Cheour, M., Huotilainen, M., Iivonen, A., ... Alho, K. (1997). Language-specific phoneme representations revealed by electric and magnetic brain responses. Nature, 385, 432-434. doi:10.1038/385432a0

Näätänen, R., Paavilainen, P., Rinne, T., \& Alho, K. (2007). The mismatch negativity $(\mathrm{MMN})$ in basic research of central auditory processing: a review. Clinical Neurophysiology, 118, 2544-2590. doi:10.1016/j.clinph.2007.04.026

Navarra, J., \& Soto-Faraco, S. (2007). Hearing lips in a second language: visual articulatory information enables the perception of second language sounds. Psychological Research, 71, 4-12. doi:10.1007/s00426-005-0031-5

Nespor, M., Peña, M., \& Mehler, J. (2003). On the different roles of vowels and consonants in speech processing and language acquisition. Lingue e Linguaggio, 2, 221247. doi: $10.1418 / 10879$

Norris, D. (1994). Shortlist - a Connectionist Model of Continuous Speech Recognition. Cognition, 52, 189-234. doi:10.1016/0010-0277(94)90043-4

Oldfield, R. C. (1971). The assessment and analysis of handedness: the Edinburgh inventory. Neuropsychologia, 9, 97-113. doi:10.1016/0028-3932(71)90067-4

Pallier, C., Bosch, L., \& Sebastian-Galles, N. (1997). A limit on behavioral plasticity in speech perception. Cognition, 64, B9-B17. doi:10.1016/S0010-0277(97)00030-9 
Pelli, D. G. (1997). The VideoToolbox software for visual psychophysics: transforming numbers into movies. Spatial Vision, 10, 437-442. doi:10.1163/156856897X00366

Peperkamp, S., \& Bouchon, C. (2011). The relation between perception and production in L2 phonological processing. In Proceedings of the Annual Conference of the International Speech Communication Association, INTERSPEECH (pp. 161-164).

Pickering, M. J., \& Garrod, S. (2013). An integrated theory of language production and comprehension. Behavioral and Brain Sciences, 36, 329-347. doi: 10.1017/S0140525X12001495

Price, C. J. (2012). A review and synthesis of the first 20years of PET and fMRI studies of heard speech, spoken language and reading. Neuroimage, 62, 816-847. doi: 10.1016/j.neuroimage.2012.04.062

Pulvermüller, F., Huss, M., Kherif, F., Moscoso del Prado Martin, F., Hauk, O., \& Shtyrov, Y. (2006). Motor cortex maps articulatory features of speech sounds. Proceedings of the National Academy of Sciences of the United States of America, 103, 7865-7870. doi: 10.1073/pnas.0509989103

Pulvermüller, F., \& Fadiga, L. (2010). Active perception: sensorimotor circuits as a cortical basis for language. Nature Reviews. Neuroscience, 11, 351-360. doi:10.1038/nrn2811

Rallo Fabra, L., \& Romero, J. (2012). Native Catalan learners' perception and production of English vowels. Journal of Phonetics, 40, 491-508. doi:10.1016/j.wocn.2012.01.001

Ramus, F. (2003). Developmental dyslexia: Specific phonological deficit or general sensorimotor dysfunction? Current Opinion in Neurobiology, 13, 212-218. doi:10.1016/S0959-4388(03)00035-7 
Ramus, F., Pidgeon, E., \& Frith, U. (2003). The relationship between motor control and phonology in dyslexic children. Journal of Child Psychology and Psychiatry and Allied Disciplines, 44, 712-722. doi:10.1111/1469-7610.00157

Rauschecker, J. P., \& Scott, S. K. (2009). Maps and streams in the auditory cortex: nonhuman primates illuminate human speech processing. Nature Neuroscience, 12, 718-724. doi: 10.1038/nn.2331

Ross, L. A., Saint-Amour, D., Leavitt, V. M., Javitt, D. C., \& Foxe, J. J. (2007). Do you see what I am saying? Exploring visual enhancement of speech comprehension in noisy environments. Cerebral Cortex, 17, 1147-1153. doi:10.1093/cercor/bhl024

Sánchez-García, C., Alsius, A., Enns, J. T., \& Soto-Faraco, S. (2011). Cross-modal prediction in speech perception. PLOS ONE, 6, 1-8. doi:10.1371/journal.pone.0025198

Sánchez-García, C., Enns, J. T., \& Soto-Faraco, S. (2013). Cross-modal prediction in speech depends on prior linguistic experience. Experimental Brain Research, 225, 499-511. doi:10.1007/s00221-012-3390-3

Scott, S. K., McGettigan, C., \& Eisner, F. (2009). A little more conversation, a little less action: candidate roles for motor cortex in speech perception. Nature Reviews. Neuroscience, 10, 295-302. doi: 10.1038/nrn2603

Sebastian-Galles, N., \& Baus, C. (2005). On the relationship between perception and production in L2 categories. In A. Cutler (Ed.), Twenty-first century Psycholinguistics: Four cornerstones (pp. 279-292). New York: Erlbaum.

Sebastian-Galles, N., Echeverría, S., \& Bosch, L. (2005). The influence of initial exposure on lexical representation: Comparing early and simultaneous bilinguals. Journal of Memory and Language, 52, 240-255. doi:10.1016/j.jml.2004.11.001 
Sebastian-Galles, N., \& Soto-Faraco, S. (1999). Online processing of native and nonnative phonemic contrasts in early bilinguals. Cognition, 72, 111-123. doi:10.1016/S0010-0277(99)00024-4

Skipper, J. I., Devlin, J. T., \& Lametti, D. R. (2017). The hearing ear is always found close to the speaking tongue: Review of the role of the motor system in speech perception. Brain and language, 164, 77-105. doi: 10.1016/j.bandl.2016.10.004

Stekelenburg, J. J., \& Vroomen, J. (2007). Neural correlates of multisensory integration of ecologically valid audiovisual events. Journal of Cognitive Neuroscience, 19, 1964-1973. doi:10.1162/jocn.2007.91213

Strange, W., \& Dittmann, S. (1984). Effects of discrimination training on the perception of /r-1/ by Japanese adults learning English. Perception \& Psychophysics, 36, 131145. doi:10.3758/BF03202673

Sumby, W. H. (1954). Visual Contribution to Speech Intelligibility in Noise. The Journal of the Acoustical Society of America, 26, 212-215. doi:10.1121/1.1907309

Schwartz, J. L., Basirat, A., Ménard, L., \& Sato, M. (2012). The Perception-for-ActionControl Theory (PACT): A perceptuo-motor theory of speech perception. Journal of Neurolinguistics, 25, 336-354. doi: 10.1016/j.jneuroling.2009.12.004

Ullman, M. T. (2004). Contributions of memory circuits to language: The declarative/procedural model. Cognition, 92, 231-270. doi:10.1016/j.cognition.2003.10.008

Vicari, S., Finzi, A., Menghini, D., Marotta, L., Baldi, S., \& Petrosini, L. (2005). Do children with developmental dyslexia have an implicit learning deficit? Journal of Neurology, Neurosurgery, and Psychiatry, 76, 1392-1397.

doi:10.1136/jnnp.2004.061093 
Vroomen, J., \& Stekelenburg, J. J. (2010). Visual anticipatory information modulates multisensory interactions of artificial audiovisual stimuli. Journal of Cognitive Neuroscience, 22, 1583-1596. doi:10.1162/jocn.2009.21308

Wacongne, C., Changeux, J.-P., \& Dehaene, S. (2012). A Neuronal Model of Predictive Coding Accounting for the Mismatch Negativity. Journal of Neuroscience, 32, 3665-3678. doi:10.1523/JNEUROSCI.5003-11.2012

Wassenhove, V. Van, Grant, K. W., \& Poeppel, D. (2005). Visual speech speeds up the neural processing of auditory speech Neurophysiological Basis of Multisensory Integration. Proceedings of the National Academy of Sciences of the United States of America, 102, 1181-1186. doi:10.1073/pnas.0408949102

Watkins, K. E., Strafella, A. P., \& Paus, T. (2003). Seeing and hearing speech excites the motor system involved in speech production. Neuropsychologia, 41, 989-994.

Winkler, I., \& Czigler, I. (2012). Evidence from auditory and visual event-related potential (ERP) studies of deviance detection (MMN and vMMN) linking predictive coding theories and perceptual object representations. International Journal of Psychophysiology, 83, 132-143. doi:10.1016/j.ijpsycho.2011.10.001 


\section{Tables:}

\begin{tabular}{|c|c|c|}
\hline Process & Tasks & $\begin{array}{c}\text { Participants } \\
\text { Included/Tested }\end{array}$ \\
\hline \multicolumn{3}{|c|}{ SESSION 1} \\
\hline L2 Perception & $\begin{array}{c}\text { Sub-lexical: Categorization, } \\
\text { Gating } \\
\text { Lexical: Lexical decision }\end{array}$ & $\begin{array}{ll}\text { Spanish dominant: } & 75 / 112 \\
\text { Catalan native: } & 20 / 20\end{array}$ \\
\hline L2 Production & $\begin{array}{c}\text { Picture naming } \\
\text { (vowels and consonants) }\end{array}$ & $\begin{array}{ll}\text { Spanish dominant: } & 62 / 112 \\
\text { Catalan native: } & 17 / 20\end{array}$ \\
\hline \multicolumn{3}{|c|}{$\underline{\text { SESSION } 2}$} \\
\hline Audio-Visual & $\begin{array}{c}\text { Cross-modal prediction } \\
\text { Behavioral (accuracy and } \\
\text { RT) } \\
\text { EEG }(\mathrm{N} 1 \text { and } \mathrm{P} 2)\end{array}$ & $\begin{array}{l}\text { Spanish dominant: 46/61 } \\
\text { Spanish dominant: 43/61 }\end{array}$ \\
\hline $\begin{array}{l}\text { Phoneme discrimination } \\
\text { sensitivity }\end{array}$ & $\begin{array}{l}\text { MMN phonemes } \\
\text { (native and unknown) }\end{array}$ & Spanish dominant: $60 / 61$ \\
\hline $\begin{array}{l}\text { Non-linguistic tone discrim- } \\
\text { ination sensitivity }\end{array}$ & $\begin{array}{c}\text { MMN acoustic } \\
\text { (frequency and duration) }\end{array}$ & Spanish dominant: $60 / 61$ \\
\hline $\begin{array}{l}\text { Non-linguistic sensory- } \\
\text { motor ability }\end{array}$ & $\begin{array}{c}\text { Drawing } \\
\text { (total and learning score) }\end{array}$ & Spanish dominant: $61 / 61$ \\
\hline
\end{tabular}

Table 1. Overview of the procedure representing the processes measured and the tasks used to measure the processes. The number of participants tested in each session and the number of participants included in the factor analysis differ because only Spanish dominant bilinguals for whom data was present in two or more processes were included in the factor analysis. Catalan native participants, for whom the experimental language was their L1, were only tested in session 1 to compare performance for the Spanish dominant bilinguals in the L2 tasks with the performance of natives. 


\begin{tabular}{|c|c|c|c|c|}
\hline Task & Measure & $\begin{array}{l}\text { Mean (Range) } \\
\text { Spanish domi- } \\
\text { nant bilinguals }\end{array}$ & $\begin{array}{l}\text { Mean (Range) } \\
\text { Catalan natives }\end{array}$ & T-test \\
\hline Categorization & $\begin{array}{l}\text { Discrimination score } \\
(0=\text { no categorization, } \\
1=\text { perfect categoriza- } \\
\text { tion })\end{array}$ & $\begin{array}{c}0.697 \\
(0.000-1.000)\end{array}$ & $\begin{array}{c}0.958 \\
(0.772-1.000)\end{array}$ & $\begin{array}{c}t(93)=3.659, \\
p<0.001\end{array}$ \\
\hline Gating & $\begin{array}{l}\text { Trials correct at last } \\
\text { gate (maximum } \\
\text { number of trials=16) }\end{array}$ & $\begin{array}{c}12.173 \\
(5.000-16.000)\end{array}$ & $\begin{array}{l}15.850 \\
(15.000- \\
16.000)\end{array}$ & $\begin{array}{c}\mathrm{t}(93)=5.717, \\
\mathrm{p}<0.001\end{array}$ \\
\hline $\begin{array}{l}\text { Lexical deci- } \\
\text { sion }\end{array}$ & $\begin{array}{c}\text { z-score compared to } \\
\text { Catalan natives }\end{array}$ & $\begin{array}{c}-4.350 \\
(-12.880-1.079)\end{array}$ & $\begin{array}{c}0.000 \\
(-2.539-0.881)\end{array}$ & $\begin{array}{c}\mathrm{t}(93)=6.117, \\
\mathrm{p}<0.001\end{array}$ \\
\hline
\end{tabular}

Table 2. L2 speech perception tasks. Mean performance (range within parentheses) in the three behavioral L2 speech perception tasks for the Spanish dominant bilinguals. For the sake of comparisons, the mean performance of a group of native speakers of the experimental language, Catalan, is also provided. T-tests show significant differences between the two participant groups. 


\begin{tabular}{cccc}
\hline Conditions & Latency & Mean (Range) & T-test against zero \\
\hline Native phoneme & $101 \mathrm{~ms}$ & $-1.182(-4.715-2.526) \mu \mathrm{V}$ & $\mathrm{t}(59)=-5.538, \mathrm{p}<0.001$ \\
Unknown phoneme & $159 \mathrm{~ms}$ & $-0.713(-9.307-3.184) \mu \mathrm{V}$ & $\mathrm{t}(59)=-2.803, \mathrm{p}=0.007$ \\
Frequency & $109 \mathrm{~ms}$ & $-1.331(-5.760-2.913) \mu \mathrm{V}$ & $\mathrm{t}(59)=-4.827, \mathrm{p}<0.001$ \\
Duration & $175 \mathrm{~ms}$ & $-0.855(-5.836-3.801) \mu \mathrm{V}$ & $\mathrm{t}(59)=-3.485, \mathrm{p}<0.001$ \\
\hline
\end{tabular}

Table 3. Discrimination sensitivity for phonemes and tones. Latency and mean (range in parentheses) MMN amplitude for the Spanish dominant bilinguals. T-tests show significant MMN for all conditions. 


\begin{tabular}{|c|c|c|c|}
\hline Measure & $\begin{array}{l}\text { Mean (Range) } \\
\text { Cross-modal continuous } \\
\text { mismatching condition }\end{array}$ & $\begin{array}{l}\text { Mean (Range) Control } \\
\text { Discontinuous mis- } \\
\text { matching condition }\end{array}$ & T-test \\
\hline Accuracy & $\begin{array}{c}0.783(0.450-1.000) \\
\text { proportions hits }\end{array}$ & $\begin{array}{c}0.829(0.600-1.000) \\
\text { proportions hits }\end{array}$ & $\mathrm{t}(45)=-4.303, \mathrm{p}<0.001$ \\
\hline $\mathrm{RT}$ & $1010(688-1444) \mathrm{ms}$ & $998(671-1315) \mathrm{ms}$ & $\mathrm{t}(45)=1.310, \mathrm{p}=0.197$ \\
\hline N1 & $\begin{array}{c}-2.932(-11.220-2.054) \\
\mu \mathrm{V}\end{array}$ & $\begin{array}{c}-2.888(-10.094-0.662) \\
\mu \mathrm{V}\end{array}$ & $\mathrm{t}(42)=-0.131, \mathrm{p}=0.897$ \\
\hline $\mathrm{P} 2$ & $\begin{array}{c}4.462(-5.242-12.720) \\
\mu \mathrm{V}\end{array}$ & $\begin{array}{c}4.263(-4.076-11.980) \\
\mu \mathrm{V}\end{array}$ & $t(42)=0.526, p=0.602$ \\
\hline
\end{tabular}

Table 4. Audio-visual prediction task. Mean (range within parentheses) behavioral measures (accuracy and reaction time, RT) and ERP components (N1 and P2) for the cross-modal continuous mismatching condition. The mean (range within parentheses) for the control condition, the discontinuous mismatching condition, is also provided. Comparisons between the two conditions were used to evaluate whether continuous visual context benefited task performance. T-tests show significant differences between the two conditions only for the accuracy. 


\begin{tabular}{cccc}
\hline Measure & Mean (Range) Spanish & Mean (Range) Catalan & T-test \\
dominant bilinguals on & natives on scale 1 (strong & \\
scale 1 (strong accent) - & accent) -5 (no accent) & \\
5 (no accent) & & \\
\hline Vowels & $3.777(2.446-4.906)$ & $4.434(3.445-4.876)$ & $\mathrm{t}(77)=3.552, \mathrm{p}<0.001$ \\
Consonants & $3.749(2.295-4.955)$ & $4.452(3.430-4.931)$ & $\mathrm{t}(77)=3.736, \mathrm{p}<0.001$ \\
\hline
\end{tabular}

Table 5. L2 speech production task. Mean (range within parenthesis) accent ratings for vowels and consonants in the L2 speech production task for the Spanish dominant bilinguals. For the sake of comparisons, the mean performance of a group of native speakers of the experimental language, Catalan, is also provided. T-tests show significant differences between the two participant groups. 


\begin{tabular}{ccc}
\hline Measure & Mean (Range) of z-scores & T-test against zero \\
\hline Total & $0.000(-1.399-0.832)$ & - \\
Learning & $0.175(-1.061-0.949)$ & $\mathrm{t}(60)=3.226, \mathrm{p}=0.002$ \\
\hline
\end{tabular}

Table 6. Sensory-motor task. Mean performance and learning (range within parenthesis) in the drawing task. The t-test shows significant learning. 


\begin{tabular}{|c|c|c|c|c|c|c|c|c|c|c|c|c|c|c|}
\hline & $\begin{array}{c}\text { L2 } \\
\text { Gat- } \\
\text { ing }\end{array}$ & $\begin{array}{l}\text { L2 } \\
\text { LDT }\end{array}$ & $\begin{array}{l}\text { MMN } \\
\mathrm{Na-} \\
\text { tive }\end{array}$ & $\begin{array}{c}\text { MMN } \\
\text { Un- } \\
\text { know } \\
n\end{array}$ & $\begin{array}{c}\text { MMN } \\
\text { Freq }\end{array}$ & $\begin{array}{c}\text { MMN } \\
\text { Dura- } \\
\text { tion }\end{array}$ & $\begin{array}{c}\text { A-V } \\
\text { Accu- } \\
\text { racy }\end{array}$ & $\begin{array}{c}\text { A-V } \\
\text { MMN } \\
\text { RT }\end{array}$ & $\begin{array}{c}\text { A-V } \\
\text { MMN } \\
\text { N1 }\end{array}$ & $\begin{array}{c}\text { A-V } \\
\text { MMN } \\
\text { P2 }\end{array}$ & $\begin{array}{l}\text { L2 } \\
\text { Vow- } \\
\text { els }\end{array}$ & $\begin{array}{c}\text { L2 } \\
\text { Con- } \\
\text { so- } \\
\text { nants }\end{array}$ & $\begin{array}{l}\text { Motor } \\
\text { Total }\end{array}$ & $\begin{array}{l}\text { Mo- } \\
\text { tor } \\
\text { Lear } \\
\text { ning }\end{array}$ \\
\hline L2 Categ & $.57^{\star \star}$ & $.44^{\star \star}$ & $.29^{\star}$ & .12 & .19 & .07 & -.07 & -.12 & -.16 & .09 & $.47^{\star \star}$ & $.50^{\star \star}$ & .13 & $-.27^{\star}$ \\
\hline L2 Gating & 1 & $.65^{\star \star}$ & $.25^{\star}$ & -.02 & .09 & .05 & .20 & -.08 & $-.31^{\star}$ & .10 & $.67^{\star \star}$ & $.63^{\star \star}$ & .00 & -.12 \\
\hline L2 LDT & & 1 & $.30^{\star}$ & .02 & .07 & -.05 & $.27^{\star}$ & .01 & -.11 & -.05 & $.66^{\star \star}$ & $.61^{\star *}$ & -.03 & .09 \\
\hline MMN Native & & & 1 & $.37^{*}$ & .21 & .19 & -.09 & .22 & .22 & .18 & $.44^{\star \star}$ & $.39^{*}$ & -.02 & -.05 \\
\hline $\begin{array}{l}\text { MMN Un- } \\
\text { known }\end{array}$ & & & & 1 & $.38^{\star}$ & .18 & -.01 & .13 & $.34^{\star}$ & .15 & .20 & .15 & .03 & .01 \\
\hline MMN Freq & & & & & 1 & $.41^{\star \star}$ & -.13 & -.06 & .09 & .07 & $.25^{\star}$ & .23 & -.14 & .01 \\
\hline MMN Duration & & & & & & 1 & -.13 & -.08 & .15 & -.16 & $.27^{\star}$ & $.25^{\star}$ & .08 & .03 \\
\hline A-V Accuracy & & & & & & & 1 & $-.34^{\star}$ & .16 & -.10 & $.30^{*}$ & $.28^{*}$ & .13 & -.06 \\
\hline A-V RT & & & & & & & & 1 & -.14 & .14 & -.16 & -.14 & $-.25^{\star}$ & $.29^{*}$ \\
\hline A-V N1 & & & & & & & & & 1 & $-.39^{\star}$ & -.09 & -.04 & -.10 & .01 \\
\hline A-V P2 & & & & & & & & & & 1 & .04 & .01 & -.05 & -.17 \\
\hline L2 Vowels & & & & & & & & & & & 1 & $.95^{\star *}$ & .04 & .03 \\
\hline $\begin{array}{l}\text { L2 Conso- } \\
\text { nants }\end{array}$ & & & & & & & & & & & & 1 & .08 & .00 \\
\hline Motor Total & & & & & & & & & & & & & 1 & $-.29^{*}$ \\
\hline $\begin{array}{l}\text { Motor Learn- } \\
\text { ing }\end{array}$ & & & & & & & & & & & & & & 1 \\
\hline
\end{tabular}

Table 7. Pair-wise correlations among the variables. The table displays the Pearson correlation coefficient $r$. One-tailed significant correlations are in bold and p values $<0.05$ and $<0.001$ are denoted with one or two asterisks respectively. 


\section{Figures}

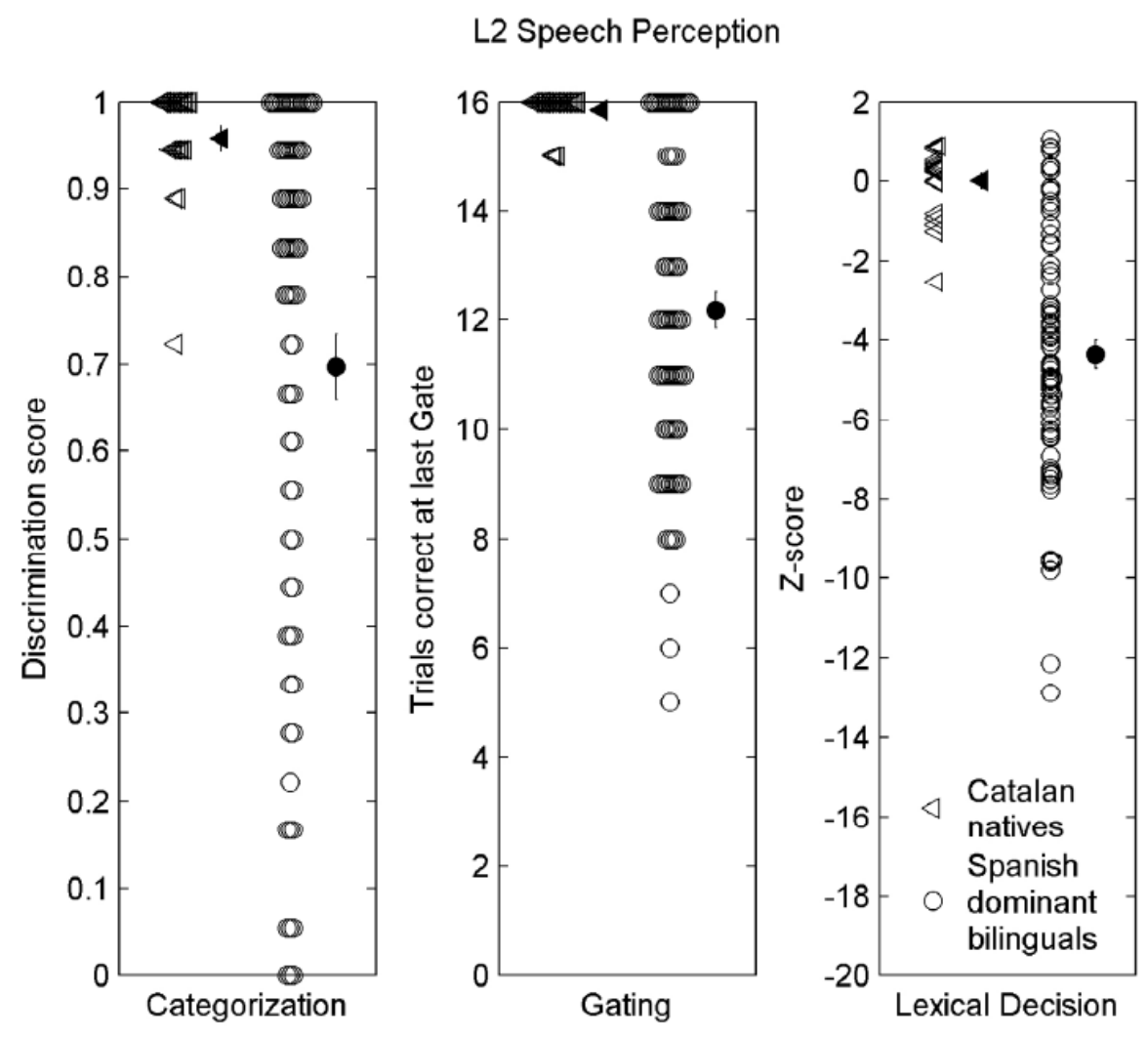

Figure 1. L2 speech perception. Individual data for the three L2 speech perception tasks: categorization, gating, and lexical decision for the Spanish dominant bilinguals and the control group: Catalan natives, for whom the experimental language was their L1. 

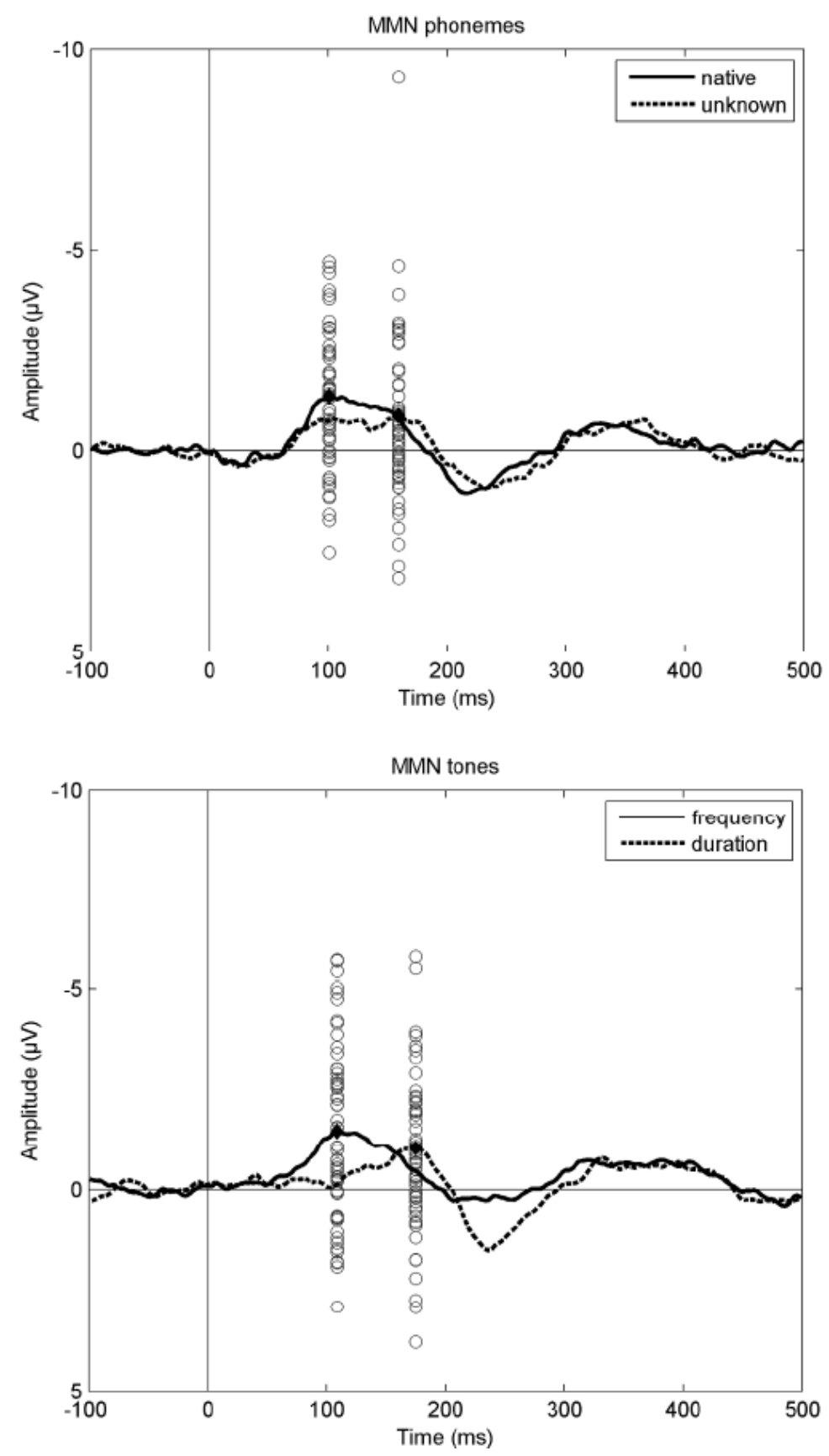

Figure 2. Discrimination sensitivity for phonemes and tones. Grandaverage difference waves and individual data (represented by the circles) at the peak of the MMN for the phoneme conditions (up): native and unknown, and the tone conditions (down): frequency and duration. 

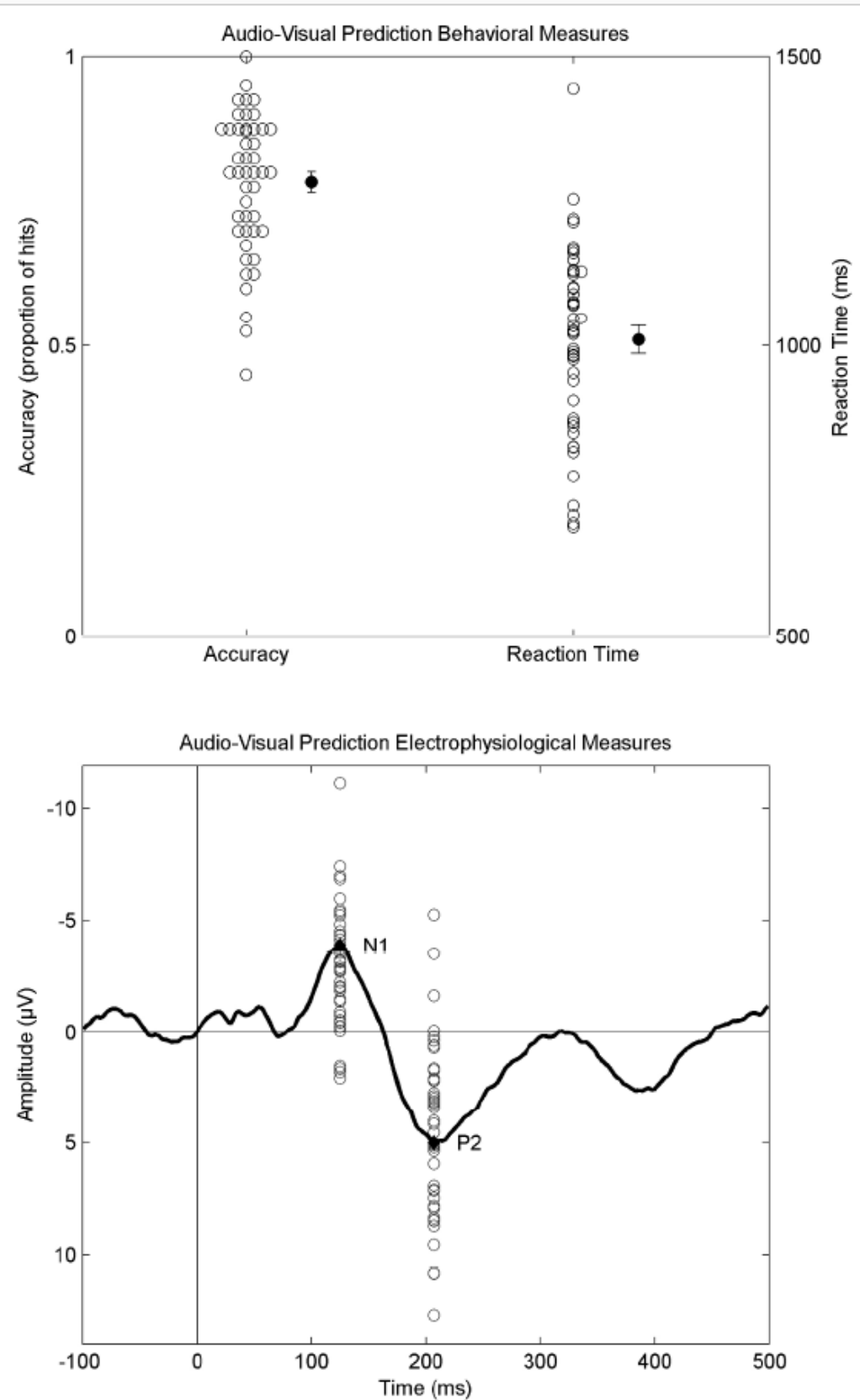

Figure 3. Audio-visual speech prediction. Individual data for the behavioral measures (up): accuracy and reaction time, and the ERP results: the grandaverage and individual data (represented by circles) at the peak for the electrophysiological measures N1 and P2 (down). 


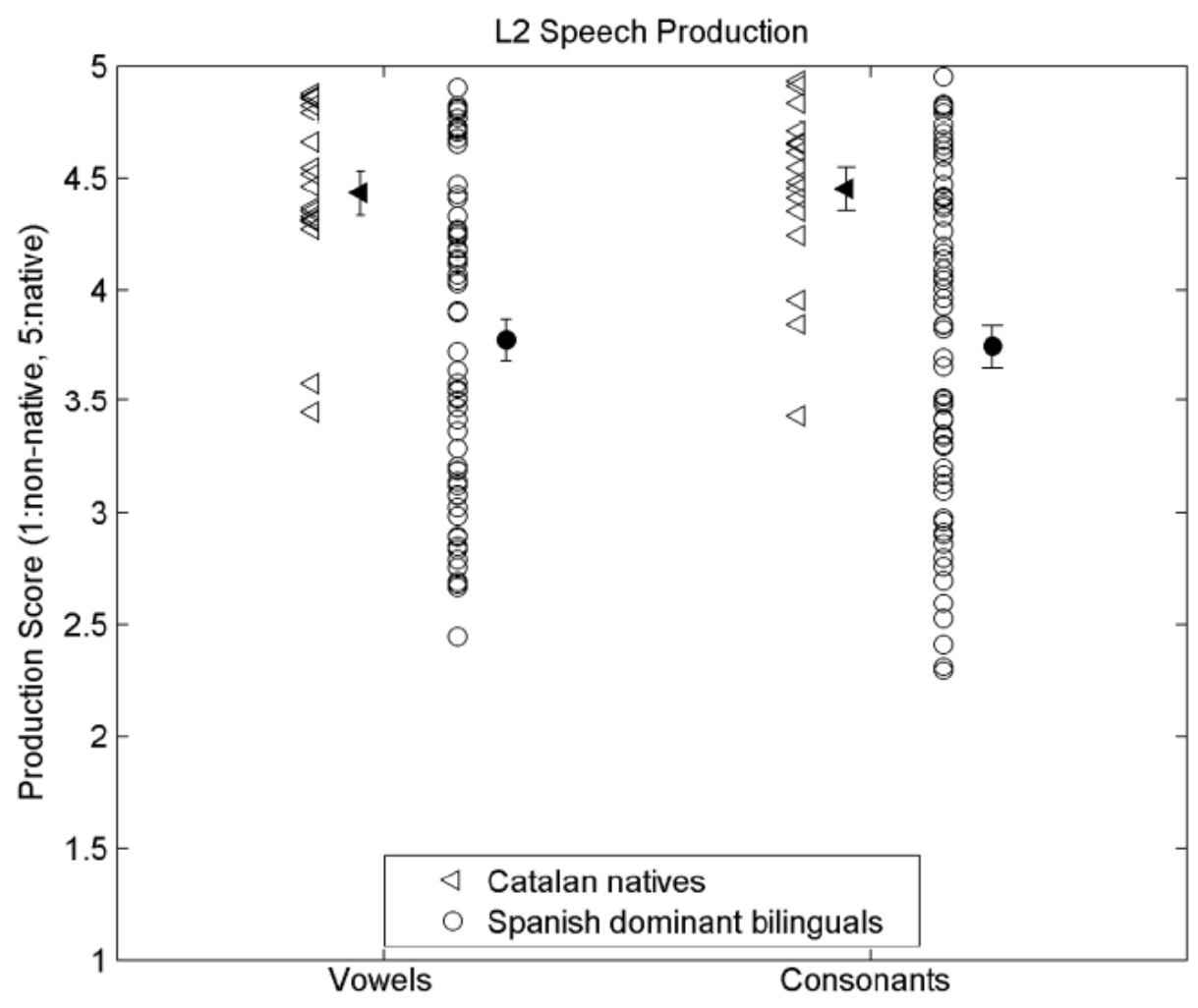

Figure 4. L2 speech production. Individual data for the L2 speech production task separately for the vowels and consonants for the Spanish dominant bilinguals and the control group: Catalan natives, for whom the experimental language was their L1. 


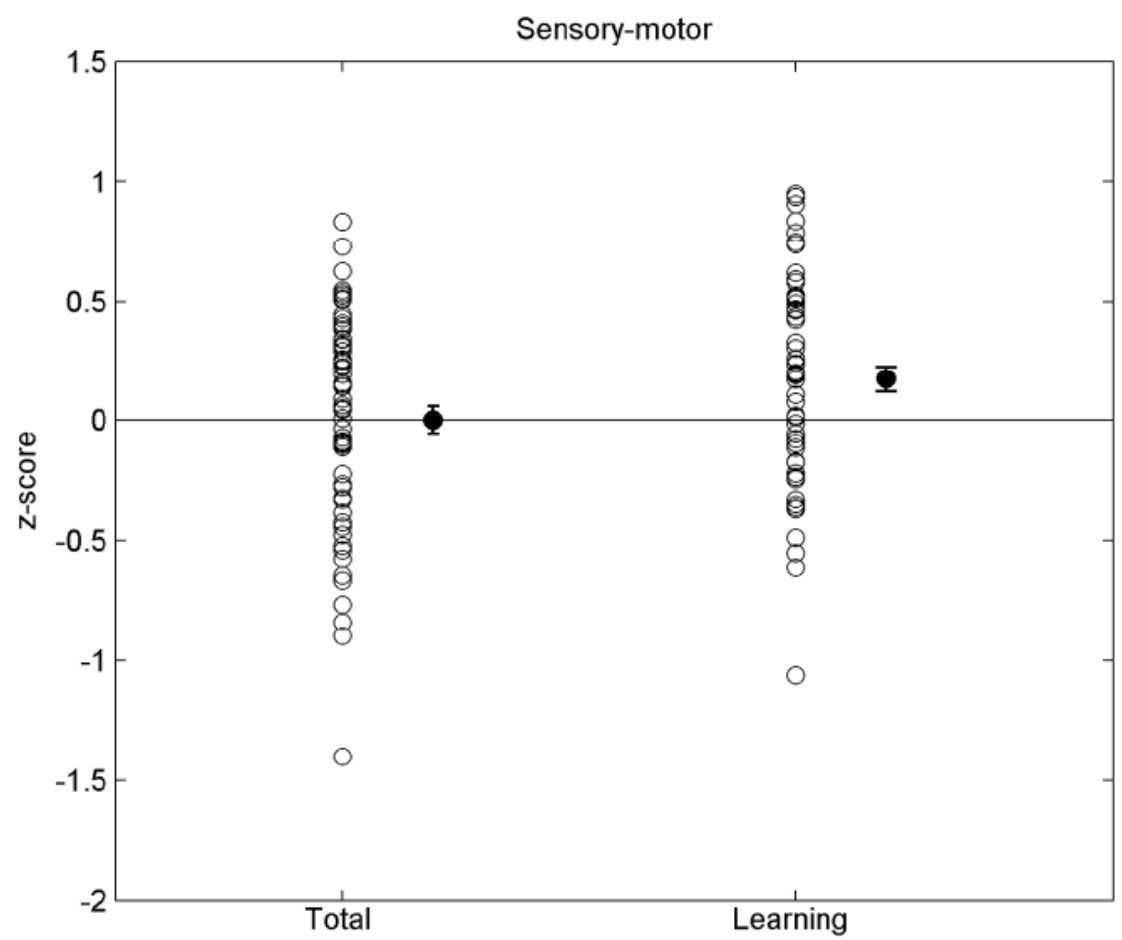

Figure 5. Sensory-motor task. Individual data for the total score and the learning score (third try minus first try) for the sensory-motor task (drawing). 


\begin{tabular}{|c|c|c|c|c|c|c|}
\hline & Process & Task & Factor1 & Factor2 & Factor3 & Factor 4 \\
\hline 1 & L2 Perception & Categorization & 0.53764 & & & \\
\hline 2 & & Gating & 0.80631 & & & \\
\hline 3 & & LDT & 0.77919 & & & \\
\hline 4 & MMN Phoneme & Native & 0.31268 & 0.53644 & & \\
\hline 5 & & Unknown & & 0.62423 & & \\
\hline 6 & MMN Tone & Frequency & & 0.53175 & & \\
\hline 7 & & Duration & & 0.44185 & & \\
\hline 8 & Audio-Visual & Accuracy & & & -0.4419 & \\
\hline 9 & & RT & & & 0.38064 & 0.60978 \\
\hline 10 & & N1 & & 0.45593 & -0.58159 & \\
\hline 11 & & P2 & & & 0.5157 & \\
\hline 12 & L2 Production & Vowels & 0.90863 & 0.31029 & & \\
\hline 13 & & Consonants & 0.85676 & & & \\
\hline 14 & Sensory-motor & Total & & & & -0.41875 \\
\hline 15 & & Learning & & & & 0.6368 \\
\hline
\end{tabular}

Figure 6. Factor analysis solution for 4 factors. Stronger colors are related to higher loadings of the variables in the factors (red: positive, blue: negative). 


\section{Appendix}
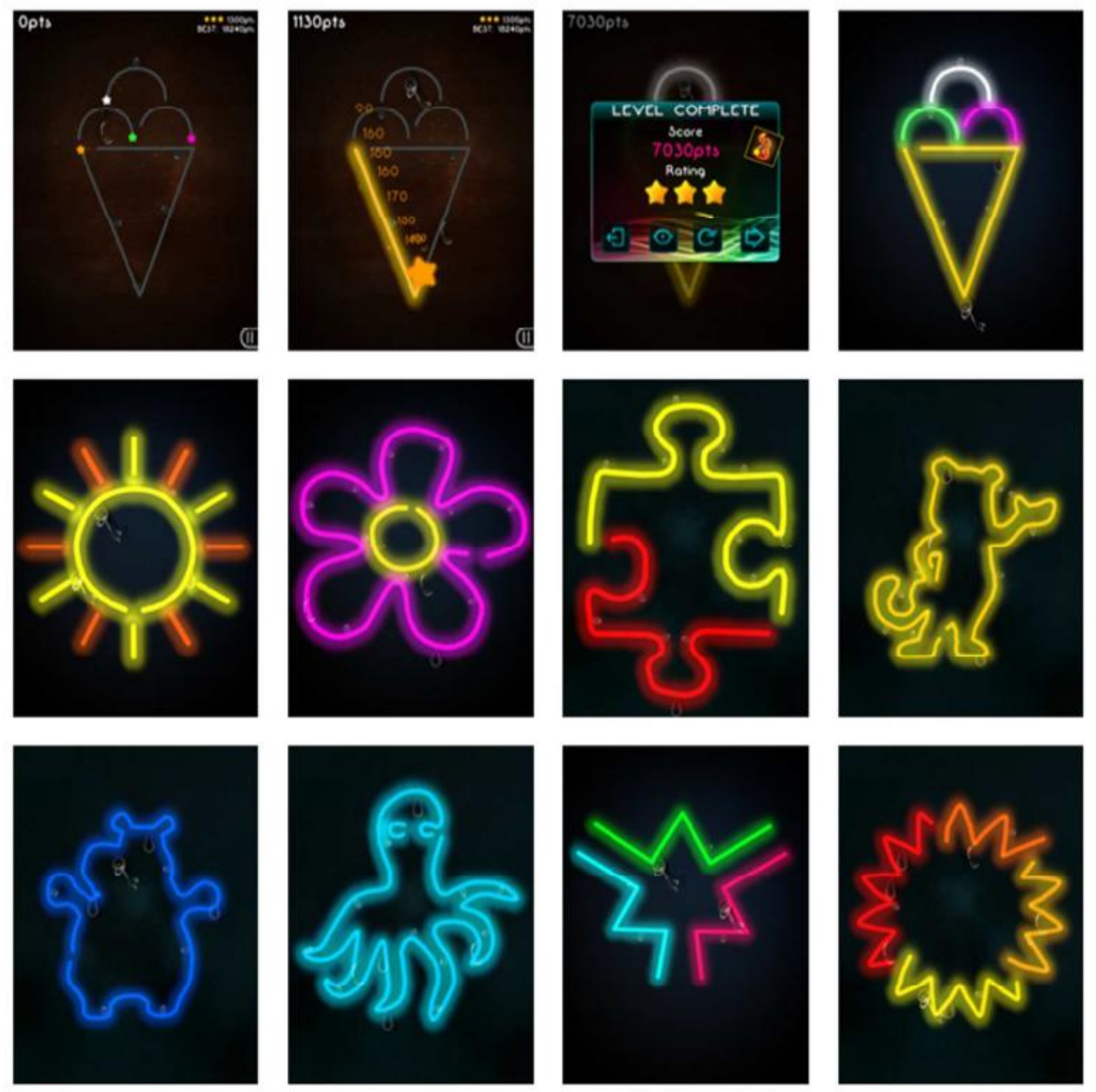

Fig-

ure A1. Sensory motor task. The first row shows an example trial for the training of the drawing task. The first image displays the beginning of the trial, when the contour of the figure appears with stars marking the starting point to draw the lines. The points obtained during the drawing are shown in the second image, the total points when finishing the drawing in the third image and the fully drawn image in the fourth image. The second and third rows show the figures used for the experimental trials. 